\title{
Transactions
}

Cite this: Dalton Trans., 2011, 40, 5643

wWW.rsc.org/dalton

PERSPECTIVE

\section{Polynuclear carbon-rich organometallic complexes: clarification of the role of the bridging ligand in the redox properties}

\author{
Karine Costuas* and Stéphane Rigaut* \\ Received 14th October 2010, Accepted 10th January 2011 \\ DOI: 10.1039/c0dt01388a
}

In this Perspective, we highlight the non-innocent behaviour of the bridging ligand in organometallic polynuclear metallic complexes displaying metal-carbon $\sigma$ bonds between the metallic units and a strongly coupled conjugated carbon-rich bridging ligand. With the help of representative experimental and theoretical studies on polymetallic systems, but also on monometallic complexes, we point out that the level of implication of the carbon rich ligand in the redox processes is very sensitive to the nature of (i) the metal(s), (ii) the ancillary ligands and (iii) the carbon-rich ligand itself, and that this participation is frequently found to be major. Consequently, the general denomination $\mathrm{M}^{(\mathrm{n}+1)}$ that is usually used for oxidized species gives the picture that only the metal density is affected, which is misleading. Moreover, for polymetallic species, these elements make the mixed valence denomination and the use of standard methodologies to rationalize intramolecular electron transfer, such as the Hush model inaccurate. Indeed, these theoretical treatments of mixed-valent complexes have at their core the assumption of metal-based redox state changes. Quantum mechanical calculations, coupled with spectroscopic methods, such as EPR spectroscopy, turn out to be a valuable suite of tools to both identify and better describe those systems with appreciable ligand redox non-innocent character. Finally, some examples and perspectives of applications for this carbon-rich type of complexes that take advantage of their peculiar electronic structure are presented.

Sciences Chimiques de Rennes, UMR 6226 CNRS - Université de Rennes 1, Campus de Beaulieu, F-35042 Rennes Cedex, France. E-mail: stephane.rigaut@univ-rennes1.fr, karine.costuas@univ-rennes1.fr

\section{Introduction}

With the "bottom-up" approach expressed by Feynman in 1959, proposing that the atoms can be arranged in a manner to build circuits of a few thousands of Ångströms across, the possible

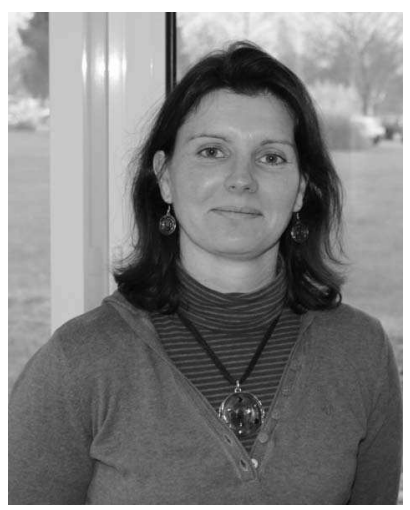

Karine Costuas
Karine Costuas was born in Brittany in the western part of France. She received her $\mathrm{PhD}$ in 2000 from the University of Rennes 1 (France), under the supervision of Prof. JeanYves Saillard and $\mathrm{Dr}$ JeanFrançois Halet. She then theoretically studied Ziegler-Natta type systems in the group of Prof. Michele Parrinello, first at the Max-Planck Institut of Stuttgart (Germany) then at the ETH of Zürich (Switzerland). She has been a researcher at the CNRS since 2002, and her work is devoted to the understanding of the relationships between structural arrangement, electronic structure and the physical properties of organometallic compounds using quantum mechanics calculations.

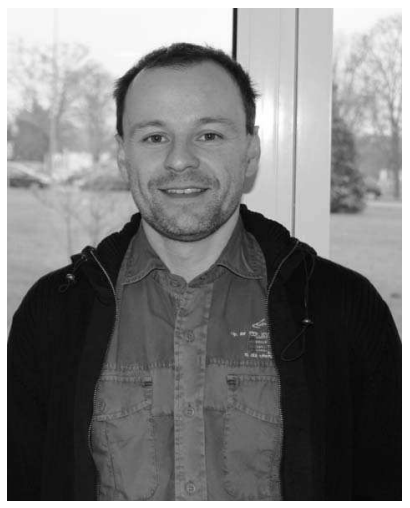

Stéphane Rigaut
Stéphane Rigaut was born in the Quercy region in the south of France. He received his PhD in 1997 from the Université Bordeaux 1 under the supervision of Prof. Didier Astruc and $\mathrm{Dr}$ Marie-Hélène Delville. After a post-doctoral position in Minneapolis (USA) with Prof. Larry L. Miller to explore vapoconductivity in dendrimers and swollen polymers, he was appointed as an assistant professor at the Université de Rennes 1 in 1998. Full Professor since 2008, he is interested in the building and the study of multifunctional organometallic redox active molecular wires and switches. 

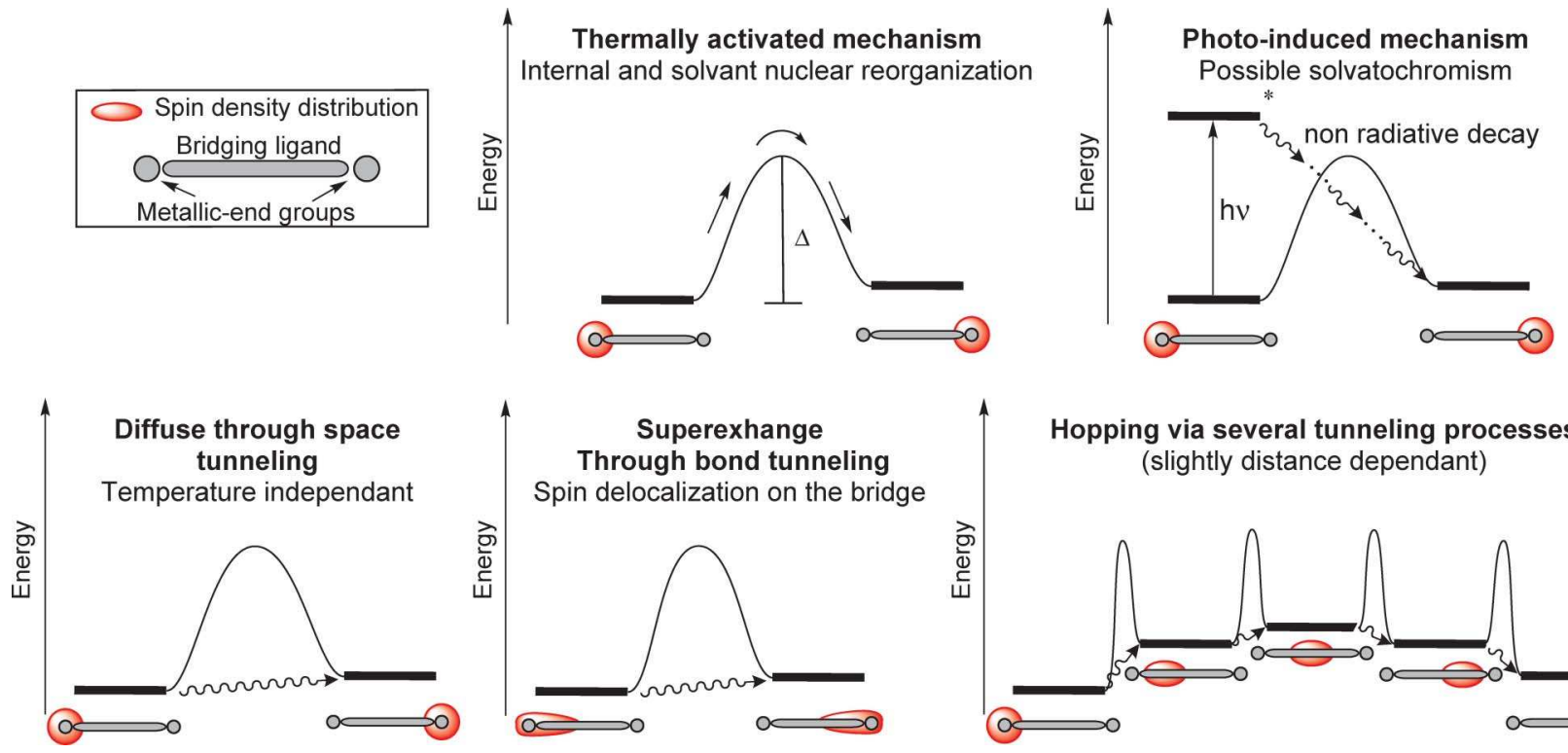

Scheme 1 Simplified description of the electron transfer mechanisms in mixed-valent bimetallic complexes.

molecular-based electronics technology has been attracting wide interest. ${ }^{1}$ Original properties and high levels of functionality may be integrated into a molecular system through molecular engineering, for instance with the incorporation of one or several metal centres permitting redox or photochemical addressing of the molecular component.

In a general way, the simplest component to consider is the molecular wire, with the sole function of facilitating the passage of current between two points. Therefore, the search for wire-like properties is connected to the study of intramolecular electron-transfer or transport (ET). ${ }^{2,3,4}$ The rational design of molecular systems capable of promoting electron transfer over technologically useful distances, and the mechanisms that control charge transfer processes are the subjects of intense debate. In the world of redox-active metal containing molecular species, the common feature is almost always to consider an oxidation or reduction of the metal centre alone. ${ }^{3}$ In the case of the so called mixed-valent compounds of the type $\left[\mathrm{M}^{(\mathrm{x})}\right]$-bridge- $\left[\mathrm{M}^{(\mathrm{x}+1)}\right]$, charge-transfer between the reduced and oxidised metal sites can occur either thermally, photochemically, via tunnelling and/or hopping (Scheme 1). Note that these mechanisms can occur concomitantly. The rationalization of the phenomenon (electronic coupling parameter) could be principally deduced from physical measurements such as absorption spectra, electron paramagnetic resonance (EPR) or infrared spectroscopy (IR) using the Marcus, Mulliken, and Hush theories with their developments. ${ }^{5}$ However, the latter are oversimplified for strongly coupled systems exhibiting significant mixing of the metal and bridging ligand-based orbitals involving the ligand in the redox processes. ${ }^{6,7,8}$

The aim of this article is precisely to draw attention to the non-innocent behaviour of the bridging ligand in organometallic polynuclear metal complexes, which occurs when metal-based and ligand-based redox orbitals are close in energy and/or overlap to interact; and that is an essential prerequisite for strong metalmetal electronic coupling across extended bridging ligands. For simplicity, we have intentionally limited this discussion to homo- dinuclear complexes displaying metal-carbon $\sigma$ bonds between the metallic units and a strongly conjugated carbon-rich bridging ligand, the latter containing exclusively carbon and hydrogen atoms, and to their first oxidized and/or reduced state with one unpaired electron. As this paper does not intend to be an extensive and exhaustive review, we have selected representative examples and emphasised some experimental and theoretical elements that suggest the participation of the bridging ligand in the redox events in various systems, to an extent that depends on the metal moieties and the bridging ligand. Importantly, for polymetallic species, these elements make inaccurate the mixed valence denomination and the use of standard methodologies, such as the Hush model, to rationalize intramolecular electron transfer and to compare different compounds. In the first part of this contribution, prior to the discussion of the complex behaviour of bimetallic and higher nuclearity assemblies, it occurred to us that it would be useful (i) to remind the reader of a number of general considerations about "mixed-valent" complexes, the means of investigation, and their limitations, (ii) to provide an insight into the electronic structure of carbon-rich complexes, and (iii) to give an overview of the real nature of the redox processes within mono-metallic species via the descriptions of their oxidized or reduced species. Finally, in the last part of the paper, we present some examples and perspectives of applications for this type of carbon-rich complexes that take advantage of their peculiar electronic structure.

\section{General considerations}

\section{Rationalization of charge transfer processes in mixed-valent systems}

Mixed-valency is a term extensively used in organic and coordination chemistry. Recently an issue of Philosophical Transactions of the Royal Society was indeed devoted to mixed-valency. In the contribution of Day et al., ${ }^{9}$ the authors remind readers that a correct term would be 'mixed oxidation state' and corresponds 
originally to the situation in which the number of electrons assigned to at least two atoms of the same element in a molecule in a localised bonding scheme is not integral. Over the years, this term was extended to systems with different atoms or groups of atoms (organic radicals) on which, formally, the unpaired electron can be localised. Marcus, ${ }^{10}$ Mulliken and Hush, ${ }^{11}$ and Robin and Day ${ }^{12}$ were the pioneers in trying to rationalize the electronic properties of such systems.

In a recent review, Keene and D'Alessandro analyzed the limitations of the original Marcus and Mulliken-Hush theories. ${ }^{13}$ They provided an overview of the theoretical developments made to date to overcome the failures of those theories. One has to consider that Hush theory, as well as the semi-classical Marcus theory, are based on the hypothesis that the unpaired electrons are completely localised on the mixed-valent sites and not on the rest of the molecule, leading to discrete reactant and product (two-state system) ${ }^{14}$ Those theories were developed in a BornOppenheimer approximation: the nuclear and electronic motions are considered as separated. The values that can be extracted from those rationalizations are the electronic coupling $H_{\mathrm{ab}}$ and the reorganization energy $\lambda$. It has to be pointed out that the access to $H_{\mathrm{ab}}$ requires the knowledge of the effective charge transfer distance, which is, in most cases, equated to the distance between the mixed-valent sites by authors..$^{15}$ The latter is truly an overestimation when the ligand participates in the electronic delocalisation. ${ }^{3 a}$ The electronic coupling evaluations can thus notably be underestimated. ${ }^{16}$

The basic limitation of the Hush theory that is to consider only one electron and two atomic (or molecular) orbitals (singleparticle approach) was further broadened by replacing orbitals by the electronic states of the initial and final systems. This approach, which is known as the generalized Mulliken-Hush theory, takes into account all the electrons of the systems (manybody phenomenon), but is still based on the hypothesis of a twostate system with weakly interacting diabatic states. ${ }^{17}$ However, in some cases, the bridging ligand is far from innocent in the localisation-delocalisation process leading to an important through-bond superexchange or hopping (see Scheme 1). This is not taken into account by the genuine theories described above and precludes their use. ${ }^{18}$ An extreme situation can even be encountered when the unpaired electron is trapped onto the bridge (ligand centred redox process). ${ }^{19}$ In such cases, the term of mixed-valency is not applicable any more and the use of MarcusHush-Mulliken theories and treatments is inappropriate.

\section{Optical intervalence charge transfer transitions}

The analysis of intervalence charge transfer transitions (IVCT) often encountered in the near-infrared (NIR) region of the absorption spectrum is the most utilized way to provide a description of electronic delocalisation in a mixed-valent system. ${ }^{13}$ Due to the existence of superexchange phenomenon mentioned above in the case of non-innocent bridging ligands where the Hush rationalization fails, a three-state treatment was proposed..$^{20}$ This results in a theory in which the band shape of the IVCT has to be considered to provide an effective electronic coupling parameter $\left(H_{\text {eff }}\right)$. However, in the cases of metal-based sites in a low-symmetry environment, the three-state model is not sufficiently sophisticated and a four-state model is at least required. In that case, several non- degenerated $\mathrm{d}$ orbitals are present leading to additional degrees of freedom (several IVCT bands). ${ }^{20}$ Moreover, in cases where spinorbit coupling is significant, interconfigurational transitions (d$\mathrm{d}$ transitions) can also be encountered in the NIR/IR region of the spectra, complicating the interpretation. ${ }^{3 a}$ Note that the four-state model is difficult to apply in systems which comprise several stable conformational isomers, the band shape being a global envelop. It is also the case when additional NIR electronic transitions exist due to ancillary ligand-centred orbitals in the $\mathrm{HOMO} / \mathrm{LUMO}$ region. It is also worth noting that the absence of solvent effect on IVCT energy is often used to classify a system as delocalised, although it can be questionable. Indeed, it was recently shown in localised systems that the solvent relaxation was slower than the electron transfer process. ${ }^{3 a, 21}$ This illustrates the often forgotten issue of the time-scale of electron transfer processes compared to the time-scale of the outer sphere relaxation and of the measurements.

For all the arguments developed here, it is clear that the analysis of optical measurements can be highly complicated ${ }^{22}$ and that the use of Mulliken-Hush theory is likely to provide erroneous information in cases where ligand redox-activity is not properly addressed.

\section{Spin-density characterisations}

The knowledge of the spin-density distribution provides considerable insight into the level of participation of the bridging ligand in the redox process (going from metal to bridging ligand centred processes). Spin-density can be experimentally measured by polarized neutron diffraction on single crystal or on powdered samples. ${ }^{23}$ EPR and Mössbauer measurements can also provide information, given that the time-scales of the experiments are taken into account.

Theoretically, access to spin density is quite straightforward in an unrestricted approximation calculation and allows evaluation of the deviation from the hypothesis needed to apply Hush and Marcus theory, thus the delocalisation onto the ligands. ${ }^{24,25}$

Some authors choose to draw their conclusions not on the spin-density but only on the basis of the atomic characters of the highest molecular orbital (HOMO) of the parent molecule for oxidized species (or lowest unoccupied (LUMO) one in the case of reduced species). This can be erroneous because of the electronic and geometric reorganization following a redox process (Scheme 2a and 2b). The same care has to be taken when trying to describe the delocalisation of the unpaired electron from the highest singly occupied orbital (SOMO) of the reduced or oxidized species. Actually, the use of an unrestricted method to calculate the electronic structure of an open-shell system implies that the energy of the $\alpha$ and $\beta$ spin-orbitals are different; the unpaired electron can thus be described by one spin-orbital or by a combination of spinorbitals above the SOMO (Scheme 2c).

It is worth emphasizing that Density Functional Theory (DFT) is particularly well suited for the quite large organometallic systems we are interested in. ${ }^{26}$ The self-interaction error inherent in the method leads to somewhat too delocalised systems, but the use of Hartree-Fock exchange in the functional mostly overcomes the problem. ${ }^{26,27}$ The calculations should be handled carefully with the choice of an appropriate starting density and initial geometry to calculate the localised isomer of the 

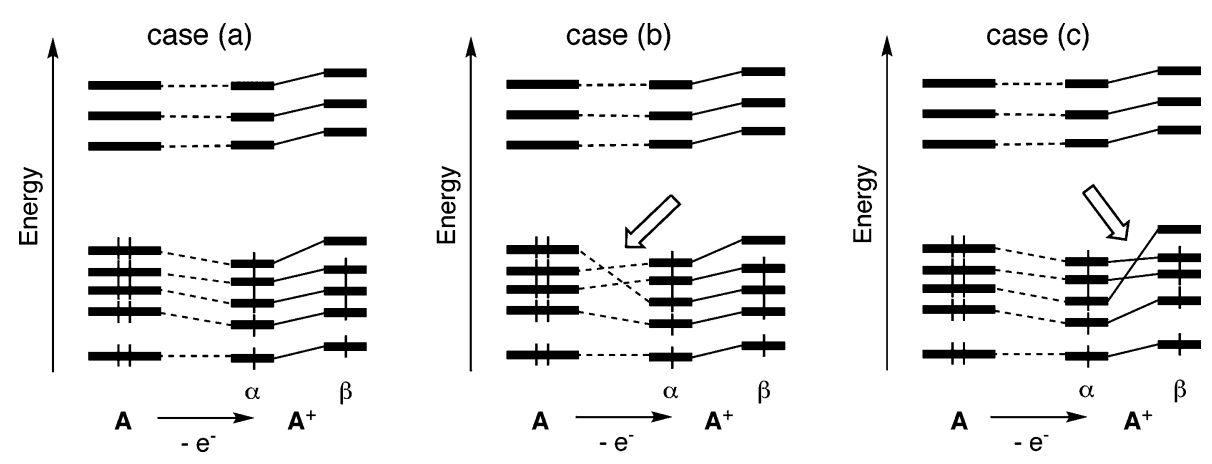

Scheme 2 Possible molecular (spin-)orbital (MO) diagrams of molecules $\mathbf{A}$ and $\mathbf{A}^{+}$. Lines between levels characterized correspondence in their nodal properties. (a) MO ordering kept upon oxidation; (b) and (c) two different reordering between spin-orbitals $\alpha$ and $\beta$ for $\mathbf{A}^{+}{ }^{30}$

considered system by using broken-symmetry or constrained DFT for example. ${ }^{28 a}$ Indeed, Kaupp and co-workers nicely showed the ability of cautiously handled DFT calculations (solvent effect, spin contamination taken into account) to allow classification of a series of mixed-valent organic compounds according to the Robin and Day scheme. ${ }^{27}$ Still, these calculations are not sufficient to completely reproduce the subtleties of real systems where the timescale (dynamic, vibration...) and the molecular environment (counterion, solvent, crystal environment in solid state) play a role in the localisation-delocalisation process. ${ }^{13,14,29}$ Nevertheless, DFT calculations provide valuable results to understand the physical properties in mixed-valent systems if one keeps in mind its limitations to avoid overinterpretation.

\section{Comments on the electrochemical tool}

With most bi-(or poly)metallic complexes bearing similar electrophores, the second electron is often more difficult to add (or to remove) than the first one, a phenomenon resulting in the observation of two successive one-electron reversible waves in cyclic voltammetry. In this section, we only wish to stress again that the comproportionation constant $K_{\mathrm{c}}$ calculated from the wave separations of the two redox events $\left(\Delta E=E_{2}-E_{1}=(-R T / F) \log K_{\mathrm{c}}\right)$ is only a thermodynamic parameter describing the stability of the intermediate (mixed-valent) state with respect to disproportionation. It is too often "cautiously" considered as an indication of electronic interaction between two identical redox active sites. Extensive delocalisation of the unpaired electron may be one contributing factor to $K_{\mathrm{c}}$, other factors including coulombic repulsion, solvation, ion-pairing with the supporting electrolyte and magnetic coupling can also play a significant role in stabilising the "mixed-valent" state. The ion-pairing and electrolyte effects were illustrated by Geiger, ${ }^{31}$ and the magnetic contribution emphasised by Lapinte. ${ }^{32}$ Additionally, we would like to emphasize here that the crucial effect of solvation was also very nicely illustrated by Hapiot and co-workers. ${ }^{33}$ A major contribution to wave separation observed in most molecules bearing two identical electrophores bound together is the large Coulombic repulsion between the two injected charges. In contrast, connection with a long saturated chain, gives rise to a single two-electron wave, resulting from the fact that the two electrophores become electronically independent and the Coulombic repulsion between the two charges in the diion becomes smaller. However, there are conjugated systems for which it has been shown that the removal of the second electron can even be significantly easier than the first one, as measured by electrochemical methods (potential inversion). Hapiot et al. ${ }^{33 a}$ demonstrated that the factors that control this potential inversion are essentially: (i) a small Coulombic repulsion due to the length of the molecule, and (ii) the concentration of the charges at both ends of the molecule of the di-ion as compared to the distribution of charge of the ion radical, thus making solvation play against disproportionation. Localisation of the charges in the di-ion indeed contributes to its stabilization by interaction with the solvent. In contrast, the delocalisation of the charge over the whole molecular framework in the ion radical plays against its stabilization by interaction with the solvent. With the extreme situation of potential inversion, this study emphasizes the fact that the magnitude of the disproportionation constant is not a mere reflection of the interaction between two redox centres as often stated despite early words of caution. ${ }^{34}$ Therefore, it should not be used as a measure of the wire-like efficiency between different systems nor in a series to compare different bridging ligands that are susceptible to participate in the redox events to accommodate the unpaired electron(s) to different extents (vide infra).

\section{Description of the bonding and electronic structures in organometallic systems bearing an $\mathrm{M}-\mathrm{C} \sigma$ bond}

An overview of the electronic structure of metallic systems containing a conjugated organic ligand is important for a better understanding of the electronic (redox) properties of carbonrich complexes. Indeed, the nature of the frontier orbitals is of particular interest in the electronic structure because most of the remarkable physical properties are accessible in those systems upon oxidation or reduction, so formally upon addition or removal of electrons from the frontier orbitals. These orbitals can be described by a simple orbital description of monometallic systems featuring a metal-carbon bond with a conjugated ligand (which can be connected to other metal centres).

The bond between the metal and the first carbon atom of the conjugated ligand can be found formally between single to triple. A general bonding orbital scheme is tentatively given in Scheme 3 in an interaction orbital diagram form. This diagram features the interaction between the frontier orbitals (FOs) of an $\mathrm{M}\left(\mathrm{L}_{x}\right)_{m}{ }^{+}$ moiety and the FOs of the conjugated carbon rich ligand $\mathrm{C}_{n}$. The charges are arbitrarily chosen to fulfil the octet rule for $\mathrm{C}_{n}{ }^{-}$. The most important interaction occurs between the FOs of each fragment and leads to the $\sigma$ bond between the metal atom and the 


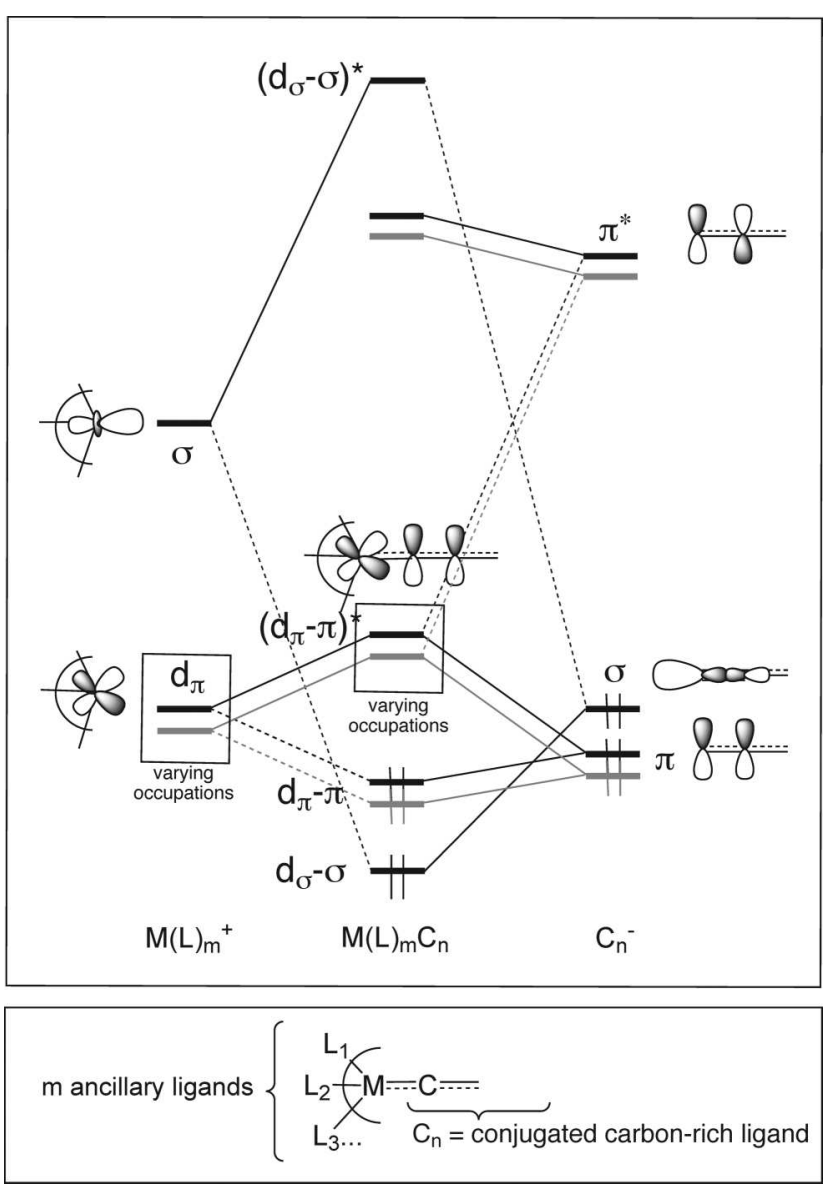

Scheme 3 Qualitative orbital interaction diagram between the frontier orbitals of a metallic fragment $\mathrm{M}(\mathrm{L})_{m}{ }^{+}$and of a carbon-rich conjugated ligand $\mathrm{C}_{n}^{-}$.

adjacent carbon atom of the $\mathrm{C}_{n}$ ligand. The other interactions are $\pi$-type in character. Depending on the metal fragment $\mathrm{M}\left(\mathrm{L}_{x}\right)_{m}{ }^{+}$, zero to two metallic FOs have the correct symmetry $\left(\mathrm{d}_{\pi}\right)$ to overlap with the $\pi$ orbitals of the $\mathrm{C}_{n}{ }^{-}$moiety. The resulting bonding orbitals are occupied $\left(\mathrm{d}_{\pi}-\pi\right)$. The antibonding ones $\left(\left(\mathrm{d}_{\pi}-\pi\right)^{*}\right)$, represented in the centre of Scheme 3, can be found from empty, leading to a triple bond $(\mathrm{M} \equiv \mathrm{C})$, to fully occupied (no additional $\pi$-bond). The second order of $\pi$ orbital interaction corresponds to the overlap between the $\left(\mathrm{d}_{\pi}-\pi\right)^{*}$ molecular orbitals with the $\pi^{*}$ vacant orbitals of $\mathrm{C}_{n}{ }^{-}$. This leads to a slight stabilization of the $\left(\mathrm{d}_{\pi}-\pi\right)^{*}$ which is commonly called metal to ligand $\pi$-back bonding.

The $\pi$-type orbitals of $\mathrm{M}\left(\mathrm{L}_{x}\right)_{m} \mathrm{C}_{n}$ described in Scheme 3 will be found in the HOMO-LUMO region of the complete electronic structure. Upon oxidation or reduction, one of these can be formally (de)populated and some physical properties as electronic delocalisation, magnetism will depend on their characteristics. One has to notice that the metal and $\mathrm{C}_{n}$ are involved in most of these orbitals leading to the qualification of $\mathrm{C}_{\mathrm{n}}$ as a non innocent ligand. ${ }^{35}$ The nature of the metal atom, of ancillary ligands $\mathrm{L}_{x}$, and of $\mathrm{C}_{n}$ will produce different electronic structures with a balanced proportion of metal and $\mathrm{C}_{n}$ in the $\mathrm{d}_{\mathrm{p}} / \pi$ orbitals. Note that $\mathrm{L}_{x}$ based orbitals can also be found in the HOMO-LUMO region.

\section{Monometallic complexes: single electron oxidation/reduction of the metal centre and/or of the organic framework?}

Several experimental studies have been aimed at rationalizing the properties (single electron localisation/delocalisaton) of oxidized acetylide complexes of the formula $\left[\mathrm{M}\left\{\mathrm{C} \equiv \mathrm{C}-1,4-\left(\mathrm{C}_{6} \mathrm{H}_{4}\right) \mathrm{X}\right\}\left(\eta^{2}-\right.\right.$ dppe $\left.)\left(\eta^{5}-\mathrm{C}_{5} \mathrm{Me}_{5}\right)\right]^{+}\left(\mathbf{1}-\mathbf{X}^{+}, \mathrm{M}=\mathrm{Fe} ; \mathbf{2}-\mathbf{X}^{+}, \mathrm{M}=\mathrm{Ru}\right)$ and trans$\left[\mathrm{Ru}\left\{\mathrm{C} \equiv \mathrm{C}-1,4-\left(\mathrm{C}_{6} \mathrm{H}_{4}\right) \mathrm{X}\right\} \mathrm{Cl}\left(\eta^{2} \text {-dppe }\right)_{2}\right]^{+}\left(3-\mathrm{X}^{+}, \mathrm{X}=\mathrm{NO}_{2}, \mathrm{CN}, \mathrm{F}\right.$, $\mathrm{H}, \mathrm{OMe}, \mathrm{NH}_{2}, \mathrm{NMe}_{2}$ ) in order to constitute a benchmark for the studies of polymetallic complexes or for the rational design of functional architectures (Chart 1). ${ }^{36,37,38}$ In this series, a strong substituent effect is experimentally observed (EPR, UV-Vis-NIR, IR, and paramagnetic NMR spectroscopies) for radical delocalisation from the metal to the arylacetylide fragment, spreading more and more on the aryl ring as the electron-withdrawing character of the substituent increases. EPR results are particularly instructive. It has been much used as an empirical rule that the principal values of the $g$-tensor may be considered as a qualitative estimation of the extent of the electron over the metal and/or over the organic ligand upon checking the departure from the free electron $g$-value. ${ }^{39}$ Accordingly, smaller $g$ anisotropy and an average $<g>$ closer to the free electron $g$-value $\left(g_{\mathrm{e}}\right)$ suggest a larger organic $\pi$-orbital character of the single electron, as encountered for metal stabilized paramagnetic species. As an illustration, the $\Delta g(<g>)$ values for the series of iron complexes $\mathbf{1 - \mathbf { X } ^ { + }}$ range from 0.524 (2.167) for $\mathrm{R}=\mathrm{NO}_{2}$ to 0.270 (2.098) for $\mathrm{R}=\mathrm{NMe}_{2}$. The calculated $g$-tensors (DFT) obtained with models of the ruthenium series fully reproduced the experimental evolution within the series (vide infra) ${ }^{38 \mathrm{~b}}$ The rationalization based on calculated spindensities is strengthened by this agreement since the spin-density data are issued from the same calculations. DFT computations revealed that the largest positive spin density is computed on the metal then on the $\alpha$-carbon atom of the acetylide, and the spin delocalisation on the aryl acetylide is clearly favoured for the most electron-releasing substituents. The spin density for the iron atom ranges from $0.8\left(\mathrm{X}=\mathrm{NO}_{2}\right)$ to $0.4\left(\mathrm{X}=\mathrm{NMe}_{2}\right)$ electrons $\left(\mathrm{e}^{-}\right)$, the rest being located on the carbon-rich ligand. For the

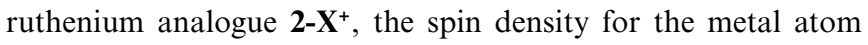

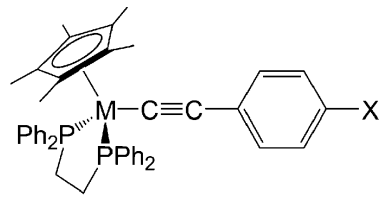

1-X: $\mathrm{M}=\mathrm{Fe}$

2-X: $M=R u$

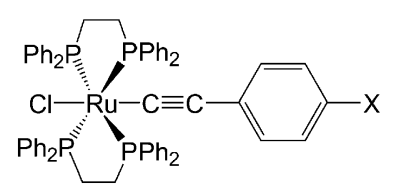

3-X

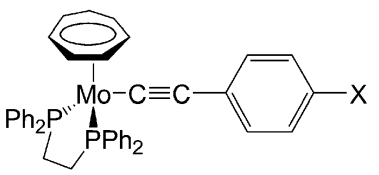

4-X

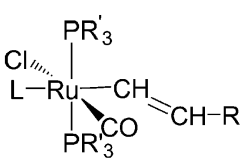

5

Chart 1 
ranges from $0.4 \mathrm{e}^{-}\left(\mathrm{X}=\mathrm{NO}_{2}\right)$ to $0.2 \mathrm{e}^{-}\left(\mathrm{X}=\mathrm{NMe}_{2}\right)$ with $\Delta g(<g>)$ values from 0.362 (2.123) to 0.135 (2.062) respectively. The larger delocalisation of the unpaired electron on the functional acetylide ligand despite very close electronic structures has to be related to the frontier MOs that are slightly more weighted on the acetylide ligand in the case of ruthenium. This also explains their enhanced reactivity. Note that the odd electron also becomes more and more carbon centred as the size of the carbon-rich ligand increases to an extent that the oxidized anthracenyl substituted complex should be described as a metal-stabilised organic radical cation. ${ }^{40}$ A relevant conclusion of these studies is that evidence is given that the EPR anisotropy alone cannot reliably be used to compare the metallic character of the unpaired electrons in different, even closely related, families of complexes. Indeed, the radical cation trans- $\left[\mathrm{Ru}\left\{\mathrm{C} \equiv \mathrm{C}-1,4-\left(\mathrm{C}_{6} \mathrm{H}_{4}\right) \mathrm{X}\right\} \mathrm{Cl}(\mathrm{dppe})_{2}\right]^{+} \mathbf{3 - \mathrm { X } ^ { + }}$ show calculated spin densities and $<g>$ values similar to those of the $\mathbf{2}-\mathbf{X}^{+}$series but with dramatically different $\Delta g$ values (i.e. from $\Delta g=1.011$ for $\mathrm{X}=\mathrm{NO}_{2}$ to $\Delta g=0.107$ for $\mathrm{X}=\mathrm{NMe}_{2}$ ). Nevertheless, the EPR measurements constitute a useful benchmark within a family of compounds where the coordination sphere is not modified. ${ }^{41}$

The isoelectronic cycloheptatrienyl molybdenum complexes $\left[\mathrm{Mo}(\mathrm{dppe})\left(\eta^{7}-\mathrm{C}_{7} \mathrm{H}_{7}\right)-\mathrm{C} \equiv \mathrm{C}-1,4-\left(\mathrm{C}_{6} \mathrm{H}_{4}\right) \mathrm{X}\right](\mathbf{4}-\mathrm{X})$ have also been studied..$^{42}$ The largely metal-centred character of the HOMO in this class of compounds has been established through a combination of experimental measurements (IR, UV-vis-NIR, EPR spectroscopies) and DFT calculations. This was rationalized in term of a strong $\delta$-interaction between molybdenum and the $\mathrm{C}_{7} \mathrm{H}_{7}$ ligand not present in the $\mathrm{Ru}\left(\eta^{5}-\mathrm{C}_{5} \mathrm{Me}_{5}\right)$ system. The calculated Mulliken spin density is found to be of $1.1 \mathrm{e}^{-}$on the Mo atom of the oxidized complexes $\mathbf{4}-\mathbf{H}^{+}$. However, chain-centred $\mathrm{C}_{\beta}$ dimerization of the diynyl radical cation $[\mathrm{Mo}(\mathrm{C} \equiv \mathrm{C}-\mathrm{C} \equiv \mathrm{C}$ $\left.\left.\mathrm{SiMe}_{3}\right)(\mathrm{dppe})\left(\eta-\mathrm{C}_{7} \mathrm{H}_{7}\right)\right]^{+}$evidences that the spin density is not insignificant on the chain in this type of compound, featuring important spin polarization. ${ }^{43}$

Particularly interesting are the vinyl ruthenium complexes $(E)-\left[\mathrm{Ru}(\mathrm{CH}=\mathrm{CHR}) \mathrm{Cl}(\mathrm{CO})\left(\mathrm{PR}_{3}^{\prime}\right)_{2} \mathrm{~L}\right]\left(5 ; \mathrm{R}={ }^{\mathrm{n}}\right.$ butyl, phenyl, 1pyrenyl; $\mathrm{R}^{\prime}=\mathrm{Ph},{ }^{\mathrm{i}} \mathrm{Pr} ; \mathrm{L}=4$-ethylisonicotinate or vacant coordination site) that display results slightly different to those obtained for the ruthenium acetylides $\mathbf{2}-\mathbf{X}$ and $\mathbf{3 - X} \cdot{ }^{44}$ In these species, the vinyl ligands contribute more strongly to, or even dominate, the anodic oxidation processes, and experimental findings are fully supported by quantum chemical calculations. For example, a small deviation of $<g>$ from $g_{\mathrm{e}}$ and small $\Delta g(<0.05)$ values are usually observed at $77 \mathrm{~K}$. It was also found that extending the conjugation within the vinyl ligand gradually modifies the nature of the frontier orbitals and thus the anodic redox processes from fully delocalised across the metal-vinyl entity to ligand dominated with smaller, yet still detectable, metal contribution. Indeed, the carbonyl band shift of the metal-bonded $\mathrm{CO}$ ligand upon mono-oxidation is significantly smaller than expected after a metal-centred oxidation process, and is further diminished as the vinyl $\mathrm{CH}=\mathrm{CH}$ entity is incorporated into a more extended $\pi$-system.

Finally, fewer studies have been carried out with cumulenic compounds of the type $[\mathrm{M}](=\mathrm{C})_{n} \mathrm{R}_{2}$ which are relatively easy to reduce. ${ }^{45}$ Addition of an extra electron was experimentally demonstrated to occur on the odd numbered carbon atoms of the chain in ruthenium complexes ( $n=3$ and 5), on the basis of EPR, IR and spin trapping experiments. ${ }^{46}$ One example is displayed in Scheme 4 with the metal allenylidene 6, for which a resolved EPR signal is observed at room temperature with $g=$ 2.0042 , characteristic of an organic radical. The experimental evidence was fully supported by the calculated spin densities suggesting that the reduced species are best described as $18-\mathrm{e}^{-}$ $\mathrm{Ru}^{\mathrm{II}}$ centres bonded to a radical ligand with an increased acetylide character rather than being a $19-\mathrm{e}^{-}$complex. It is also worth noting that one-electron reduction of the ruthenium bis(allenylidene) complex 7 leads to a symmetric radical that has one unpaired electron delocalised identically over both trans carbon-rich chains (Scheme 4). Oxidation of ruthenium ${ }^{46}$ or manganese ${ }^{47}$ cumulenic species was also observed. On the basis of calculations and of reactivity, the processes were mainly assigned to the metal atom with a ligand participation that depends on the nature of the metal, support and bridging ligands.

As a first conclusion, we would like to emphasise that these experimental observations supported by theoretical calculations (vide supra) shed light on the fact that metal-centred oxidation is not observed, and that the general denomination $\mathbf{M}^{(n+1)}$ or $\mathbf{M}^{(n-1)}$ often used for oxidized/reduced species, and giving the picture

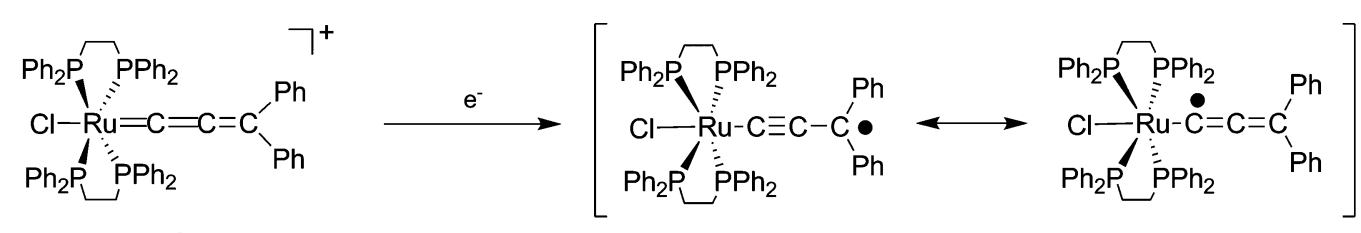

6

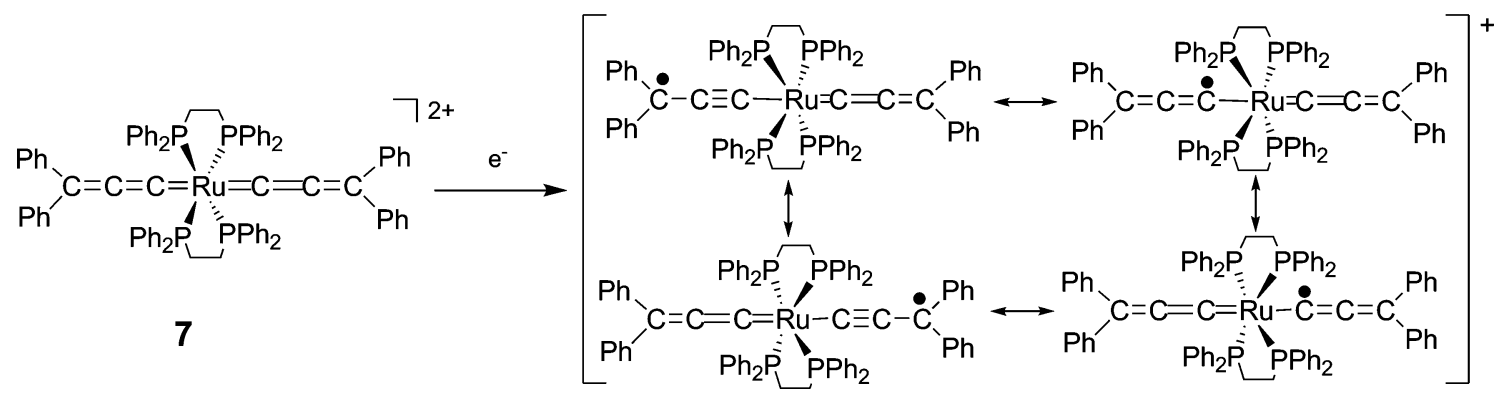

Scheme 4 
that only the metal density is affected, is questionable and might be highly misleading.

\section{Bimetallic complexes: single electron oxidation/reduction of the metal units and/or of the organic bridging ligand?}

Numerous bimetallic iron complexes of the type $\left[\left(\eta^{5}-\right.\right.$ $\left.\mathrm{C}_{5} \mathrm{Me}_{5}\right)(\mathrm{dppe}) \mathrm{Fe}-\mathrm{C} \equiv \mathrm{C}-\mathrm{R}-\mathrm{C} \equiv \mathrm{C}-\mathrm{Fe}(\mathrm{dppe})\left(\eta^{5}-\mathrm{C}_{5} \mathrm{Me}_{5}\right)$ ] (8) have been studied (Chart 2) ${ }^{48}$ Depending on the nature of the spacer, EPR spectroscopy of the first oxidized state $\mathbf{8}^{+}$(radical cation) displayed a signal with various anisotropy $\Delta g$ and $<g>$ factor values deviating more or less from the free electron one. A large anisotropy $(\Delta g=0.530)$ was detected in the signal obtained for the complex bearing the non conjugated spacer $\mu-\mathrm{C} \equiv \mathrm{C}-1,3-\mathrm{C}_{6} \mathrm{H}_{4}-$ $\mathrm{C} \equiv \mathrm{C}$, with $\langle g>=2.505$, significantly shifted from that of the free electron value. These characteristics are close to those of the monometallic systems, thus consistent with an electron highly localised on one metal moiety on the EPR time scale. ${ }^{28 b}$ However, $\Delta g(<g>)$ values as low as $0.060(2.102)$ for the $\mu-\mathrm{C} \equiv \mathrm{C}-\mathrm{C} \equiv \mathrm{C}$ spacer, 0.083 (2.052) for $\mu-\mathrm{C} \equiv \mathrm{C}-1,4-\mathrm{C}_{14} \mathrm{H}_{8}-\mathrm{C} \equiv \mathrm{C}$ (anthracene), 0.107 (2.053) for $\mu-\mathrm{C} \equiv \mathrm{C}-2,5-\mathrm{C}_{4} \mathrm{H}_{2} \mathrm{~S}-\mathrm{C} \equiv \mathrm{C}, 0.109$ (2.054) for $\mu$ $\mathrm{C} \equiv \mathrm{C}-(\mathrm{C} \equiv \mathrm{C})_{2}-\mathrm{C} \equiv \mathrm{C}, 0.168$ (2.091) for $\mu-\mathrm{C} \equiv \mathrm{C}-1,4-\mathrm{C}_{6} \mathrm{H}_{4}-\mathrm{C} \equiv \mathrm{C}$ reveal a decreased participation of the metal $\mathrm{d}$ atomic orbitals to the magnetic orbital in this series, i.e., with the same coordination environment for the metal in all complexes. As it can be expected from EPR measurements, DFT calculations show that as the size of the conjugated bridge increases, the metallic (bridging ligand) participation in the redox process decreases (increases) from 0.64 (0.38) $\mathrm{e}^{-}$for the $\mu-\mathrm{C} \equiv \mathrm{C}-\mathrm{C} \equiv \mathrm{C}$ bridge, $0.54(0.45) \mathrm{e}^{-}$for $\mu-\mathrm{C} \equiv \mathrm{C}-$ $1,4-\mathrm{C}_{6} \mathrm{H}_{4}-\mathrm{C} \equiv \mathrm{C}, 0.44(0.52) \mathrm{e}^{-}$for $\mu-\mathrm{C} \equiv \mathrm{C}-(\mathrm{C} \equiv \mathrm{C})_{2}-\mathrm{C} \equiv \mathrm{C}$, to 0.38 (0.68) $\mathrm{e}^{-}$for the $\mu-\mathrm{C} \equiv \mathrm{C}-1,4-\mathrm{C}_{14} \mathrm{H}_{8}-\mathrm{C} \equiv \mathrm{C}$ linker, with a repartition over the entire conjugated path of the bridge. In the latter example, the oxidation is even found to mainly occur on the chain. It is worth noting that similar EPR results are also observed for butadienediyl complexes such as $\mathbf{9}^{+}$, i.e., with $\Delta \mathrm{g}(<g>)$ values of 0.063 (2.059). ${ }^{49}$

For the rhenium complex $\left[\left(\eta^{5}-\mathrm{C}_{5} \mathrm{Me}_{5}\right) \operatorname{Re}(\mathrm{NO})\right.$ $\left.\left(\mathrm{PPh}_{3}\right)_{2}(\mathrm{C} \equiv \mathrm{CC} \equiv \mathrm{C})\right](\mathbf{1 0}){ }_{,}^{50}$ oxidation appears to be a little less metal-centred than with the iron species, with an estimated spin density of $0.50 \mathrm{e}^{-}$on the rhenium atoms $\left(0.25 \mathrm{e}^{-} \times 2\right)$ and $0.52 \mathrm{e}^{-}$on the $\mathrm{C}_{4}$ chain. ${ }^{51}$ Experimentally, with longer chains, decomposition occurs in the oxidation states. As the carbon chain becomes more exposed, a carbon-carbon bond forming dimerization was proposed. This is in line with calculations showing that in the monocationic state for chain lengths of more than eight carbon atoms, the electron spin is found to be mainly localised on specific atoms of the chain and not on the metal centres. Therefore, the spin delocalisation onto the chain is again found to increase, as the chain gets longer. ${ }^{52}$

In the ruthenium series $\left[\left\{\left(\eta^{5}-\mathrm{C}_{5} \mathrm{Me}_{5}\right)(\mathrm{dppe}) \mathrm{Ru}\right\}_{2}(-\mathrm{C} \equiv \mathrm{C}-)_{n}\right]$ (11), with $n=2$, both the metal centres and the carbon atoms of the $\mathrm{C}_{4}$ bridge are affected with the removal of one electron housed

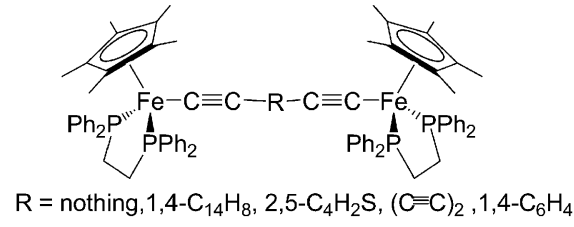

8



11: $M=R u ; n=1,2$

12: $M=O s ; n=1,2$

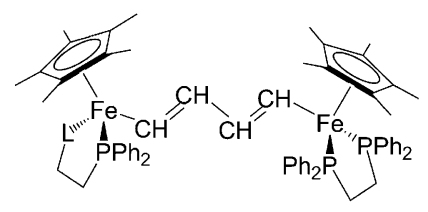

9



13: $\left.1,3-\mathrm{C}_{6} \mathrm{H}_{4} ; \mathrm{Ru}\right]=\left[\left(\mathrm{C}_{5} \mathrm{Me}_{5}\right) \text { Rudppe or Ru(dppe }\right)_{2} \mathrm{Cl}$

14: $\left.1,4-\mathrm{C}_{6} \mathrm{H}_{4} ; \mathrm{Ru}\right]=\mathrm{Ru}(\mathrm{dppe})_{2} \mathrm{Cl}$

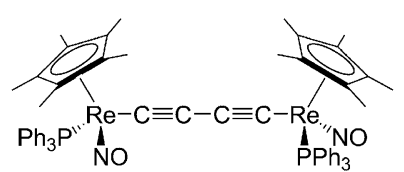

10

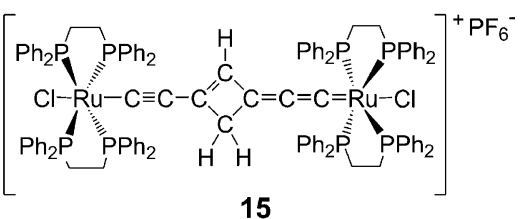

15

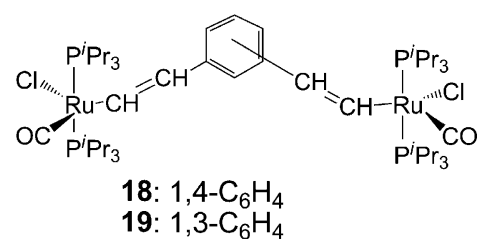

17<smiles></smiles>

19: $1,3-\mathrm{C}_{6} \mathrm{H}_{4}$

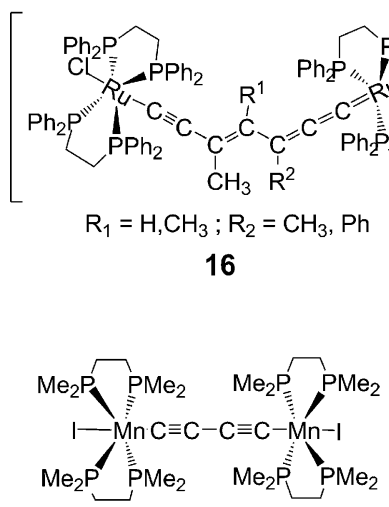

20

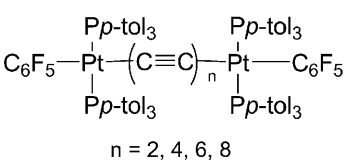

21

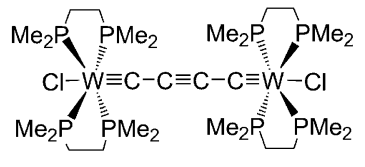

22

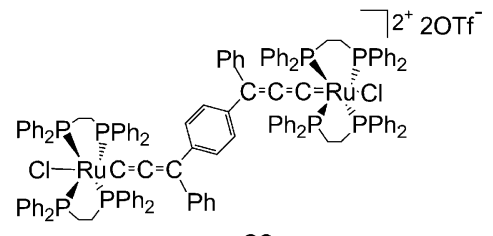

23

Chart 2 
in MOs delocalised over all atoms of the $\mathrm{Ru}-\mathrm{C}_{4}-\mathrm{Ru}$ chain. ${ }^{53}$ EPR spectroscopy measurements show a value of $\langle g>=2.096$ with $\Delta g=0.232$, which is indicative of the ligand participation (vide infra). DFT calculations show that the single electron is less localised on the ruthenium atoms than on the chain $(0.352$ vs. $\left.0.562 \mathrm{e}^{-}\right)$. With the $\mathrm{C}_{2}$ analogue $(n=1)$, the participation of the chain is also significant. ${ }^{54}$ It is worth noting that, for the latter complex, a spectroelectrochemical investigation has revealed an intense band near $14300 \mathrm{~cm}^{-1}$ after one electron oxidation attributed to a $\mathrm{Ru}(\mathrm{d}) / \mathrm{C}_{2}(\pi) \rightarrow\left[\mathrm{Ru}(\mathrm{d}) / \mathrm{C}_{2}(\pi)\right]^{*}$ transition, rather than to an IVCT band. These observations have also been rationalized using DFT calculations. They collectively indicate that the frontier orbitals are delocalised over both group 8 metal centres and the carbon chain. An overall similar behaviour is observed for the osmium analogues $12 .{ }^{55}$ The electronic structures of related acetylide complexes including an aromatic spacer such a $\left[1,3-\{[\mathrm{Ru}]-\mathrm{C} \equiv \mathrm{C}\}_{2}-\mathrm{C}_{6} \mathrm{H}_{4}\right](\mathbf{1 3})$ with $[\mathrm{Ru}]=\left(\eta^{5}-\mathrm{C}_{5} \mathrm{Me}_{5}\right)(\mathrm{dppe}) \mathrm{Ru}$ or trans-ClRu(dppe $)_{2}$ ) have been investigated in their available redox states. ${ }^{56}$ The bridging aryl moiety is found to be heavily involved in the first oxidation process, more than in the closely related iron compounds. Consequently, the unique observed lowenergy (NIR) absorption band is better described as arising from charge transfer transitions from a metal-acetylide donor to a metal-phenylacetylide acceptor than in terms of IVCT transitions. The spin density in this localised systems is distributed over only one ruthenium moiety $\left(0.36 \mathrm{e}^{-}\right.$for $\left(\eta^{5}-\mathrm{C}_{5} \mathrm{Me}_{5}\right)\left(\mathrm{PH}_{3}\right)_{2} \mathrm{Ru}$, and 0.28 $\mathrm{e}^{-}$for trans- $\left.\mathrm{ClRu}\left(\mathrm{PH}_{3}\right)_{2}\right)$, on the corresponding $\mathrm{C}_{\alpha}\left(0.02 \mathrm{e}^{-}\right.$, and $\left.0.07 \mathrm{e}^{-}\right)$and $\mathrm{C}_{\beta}\left(0.31 \mathrm{e}^{-}\right.$, and $\left.0.26 \mathrm{e}^{-}\right)$atoms, and on the aryl ring system $\left(0.31 \mathrm{e}^{-}\right.$, and $\left.0.35 \mathrm{e}^{-}\right)$. A large bridging ligand participation is also observed for the $-\mathrm{C} \equiv \mathrm{C}-1,4-\mathrm{C}_{6} \mathrm{H}_{4} \mathrm{C} \equiv \mathrm{C}$ - linker with the $\mathrm{ClRu}(\mathrm{dppe})_{2}$ system (14). ${ }^{57}$ For the first oxidized species, at $298 \mathrm{~K}$, an isotropic, broad signal was found at $g=2.047$ which did not show any hyperfine splitting. The low-temperature spectrum exhibits rhombic symmetry with no HFS and $\Delta g=0.163$; the averaged $g$ value $g_{\text {iso }}=2.067$ fits roughly to the $g_{\text {iso }}$ value measured at $298 \mathrm{~K}$. Since the EPR measurements reveal marked alkynyl ligand contribution to the delocalisation of the unpaired electron in the oxidized state, the intense long-wavelength bands could not be assigned to IVCT bands. Accordingly, the authors proposed an alternative assignment as intra-ligand transitions.

With the "trans-ClRu(dppe) $)_{2}$ " metal system, details of the characterizations of original odd numbered carbon bridged complexes in different oxidation states with an annelated trans $-\left[\mathrm{Cl}(\mathrm{dppe})_{2} \mathrm{Ru}=\mathrm{C}=\mathrm{C}=\mathrm{C}-\mathrm{CH}=\mathrm{C}\left(\mathrm{CH}_{2}\right)-\right.$ $\left.\mathrm{C} \equiv \mathrm{C}-\mathrm{Ru}(\mathrm{dppe})_{2} \mathrm{Cl}\right]\left[\mathrm{PF}_{6}\right] \quad$ (15) complex and three "W" shaped adducts trans- $\left[\mathrm{Cl}(\mathrm{dppe})_{2} \mathrm{Ru}-\mathrm{C} \equiv \mathrm{C}-\mathrm{C}\left(\mathrm{CH}_{3}\right)=\mathrm{C}\left(\mathrm{R}_{2}\right)-\right.$ $\left.\mathrm{C}\left(\mathrm{R}_{1}\right)=\mathrm{C}=\mathrm{C}=\mathrm{Ru}(\text { dppe })_{2} \mathrm{Cl}\right]\left[\mathrm{BF}_{4}\right](\mathbf{1 6})\left(\mathrm{R}_{1}=\mathrm{Me}, \mathrm{Ph} ; \mathrm{R}_{2}=\mathrm{H}\right.$, $\mathrm{Me}$ ) have been reported. These studies provide a picture of the electron delocalisation between the two ruthenium termini in the reduced and oxidized states by means of EPR, IR, UV-vis, and NIR spectroscopies, and computational studies (DFT). All together, the results demonstrate that the $\mathrm{C}_{7}$ bridging ligand spanning the metal centres by almost $12 \AA$ is implicated in both redox processes, with no tendency for spin localisation on one of the halves (Fig. 1). ${ }^{58}$ For example, with the "W" shaped adduct $\mathbf{1 6}$ with $\mathrm{R}_{1}=\mathrm{H}, \mathrm{R}_{2}=\mathrm{H}$, it was first established that in the reduced state the single electron is delocalised mainly over the carbon chain with very little metal contribution. Only the isotropic $g$-value in fluid solution could be estimated for this reduced neutral species (2.0032), and is very close to that of the free electron. Furthermore, the hyperfine splitting illustrates the electron delocalisation (the active set of nuclei being considered is: $8 \mathrm{P}, 2 \mathrm{Ru}$, and $1 \mathrm{H}$ ). Within the oxidized form, the odd electron is fully delocalised over the chain and the metal centres. The rhombic EPR spectra recorded at $77 \mathrm{~K}$ and $4 \mathrm{~K}$ exhibit quite low $g$ anisotropy (0.160) and the average $<g>$ factor of 2.0064 is not strongly shifted from the free electron $g$-value. Accordingly, computed spin densities on simplified models show full localisation of the unpaired electron on the carbon chain in the reduced state, and half of the unpaired electron lies on the $\mathrm{Ru}$ centres and half on the bridging ligand in the oxidized form (Fig. 1). The low energy bands observed are rather ascribed to $\pi$ to $\pi^{*}$ transitions in this extended system than to intervalence transfer (IT) bands.

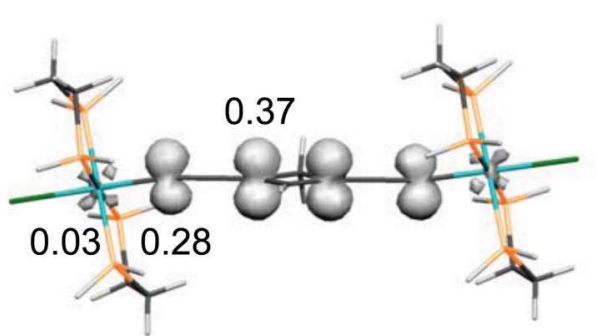

$15-\mathrm{H}$

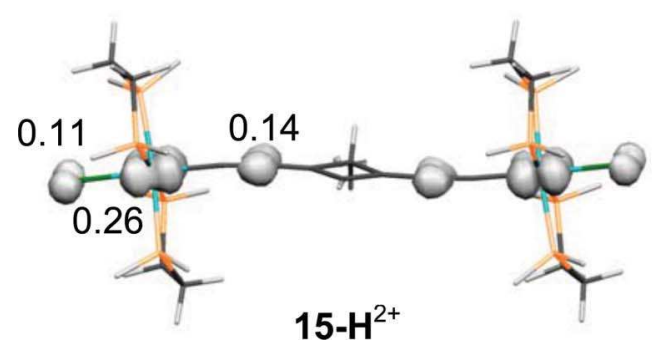

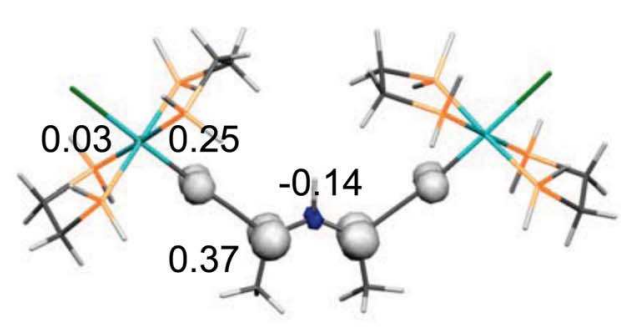

16-H

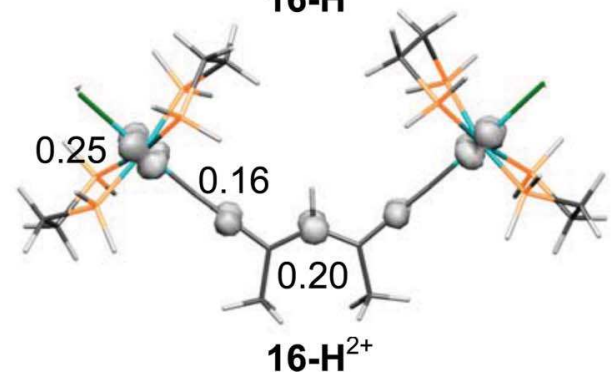

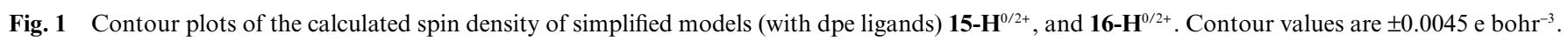


Polyyn-diyls capped by the bimetallic $\mathrm{Ru}_{2}(\mathrm{ap})_{4}$ termini (ap $=2$ anilinopyridinate), that is $\left[\mathrm{Ru}_{2}(\mathrm{ap})_{4}\right]-(\mathrm{C} \equiv \mathrm{C})_{n}-\left[\mathrm{Ru}_{2}(\mathrm{ap})_{4}\right](n=1-4$, 6) can be either reduced or oxidized. The frontier orbitals of the bis-ruthenium moieties can be considered as in-phase and outof-phase combinations of $\mathrm{ML}_{5}$ and $\mathrm{ML}_{4}$ moieties. This results in a set of FO which have $\sigma$ and $\mathrm{d}_{\pi}$ symmetries similar to those of the trans-[Cl(dppe) $\left.)_{2} \mathrm{Ru}\right]$ group (see Scheme 3). Even though no EPR or spin density calculations were provided, one can suspect a non-negligible participation of the carbon-rich bridge. ${ }^{59}$ This assumption is based on the MO plots provided by the authors which show, for the last HOMOs and first LUMOs, noticeable lobes on the carbon atoms of the bridge. Of course, the choice of the iso-surface can be misleading, and the energetic and geometric relaxations upon a redox process can modify the interpretation based on the hypothesis that a redox process is a simple electron removal or addition in the parent frontier MOs. Also note that earlier work on molecular systems composed of a central $\mathrm{Ru}_{2}(\mathrm{DMBA})_{4}$ type unit connected by different polyynyl bridges to ferrocenyl units already suggested delocalisation onto the bridge in the mixed-valent species. ${ }^{60}$

With meta-bridged divinylruthenium complex $(E, E)-\left[\left\{\left(\mathrm{PPh}_{3}\right)_{2}\right.\right.$ (CO) $\mathrm{Cl}(4-\mathrm{EtOOCpy}) \mathrm{Ru}\}_{2}\left(\mathrm{~m}-1,3\left(\mathrm{HC}=\mathrm{CH}-\mathrm{C}_{6} \mathrm{H}_{4}-\mathrm{CH}=\mathrm{CH}\right)\right]$ (17) ${ }^{61}$ oxidation processes also involve the organic bridge. In fluid solution and at room temperature, it displays an intense, slightly broad isotropic spectrum with a $g$-value of 2.0201 that is somewhat larger than expected for a purely organic paramagnetic species. At ca. $220 \mathrm{~K}$, a weak rhombic splitting prevails $\left(g_{x}=2.0326, g_{y}=\right.$ $\left.2.0207, g_{z}=2.0107\right)$. The small oxidation shift of the $\mathrm{CO}$ vibration stretch (by $40 \mathrm{~cm}^{-1}$ ) also suggests the low metal contribution to the redox orbital and that a significant fraction of the positive charges is accommodated at the divinylphenylene ligand. Therefore, the authors concluded that those cations are predominantly organiccentred radicals with a minor, but clearly detectable, contribution of metal atoms to the spin bearing SOMO. Further insights into the electronic structure obtained by DFT calculations (on a simplified model bearing $\mathrm{PH}_{3}$ ) showed that in the HOMO, the contribution of the bridge $(81 \%)$ clearly dominates that of the ruthenium atoms (17\%), and spin unrestricted calculations on the radical cation confirm that the HOMO composition faithfully carries over to spin-densities. These results slightly contrast with the analogous acetylides complexes (vide supra). Note that the oxidation potential of $\mathbf{1 7}$ is substantially lower than those of alkylated oligovinylphenylenes, and that the presence of the metal moieties endows the cation with stability that is usually not encountered in their purely organic counterparts. Interestingly, with more electron releasing phosphines, the divinylphenylene-bridged diruthenium complex $(E, E)-\left[\left\{\left(\mathrm{P}^{i} \mathrm{Pr}_{3}\right)_{2}(\mathrm{CO}) \mathrm{ClRu}\right\}_{2}\left(\mu-\mathrm{HC}=\mathrm{CHC}_{6} \mathrm{H}_{4} \mathrm{CH}=\mathrm{CH}-\right.\right.$ 1,4)] (18) shows a higher electron density at the metal atoms that increases the contribution of the metal end-groups to the bridgedominated occupied frontier orbitals and stabilizes the various oxidized forms with respect to the $\mathrm{PPh}_{3}$-containing analogue. Nevertheless, strong EPR signals and nearly isotropic $g$ tensors were still observed for the monocations in fluid and frozen solutions, and electronic transitions observed for the mono- and di-oxidized forms closely resemble those of donor substituted phenylenevinylene compounds. DFT calculations showed that the spin density spreads over both metal centres and the bridge. Interestingly, with the $\mathrm{P}^{i} \mathrm{Pr}_{3}$ meta analogue 19, as observed with the dppe system 13, the spin density is localised just on one $\mathrm{Ru}-$
$\mathrm{CH}=\mathrm{CHPh}$ subunit, even though the oxidation mainly involves the divinylphenylene bridging ligand.

Several manganese complexes have been studied and fast electron delocalisation was suggested. ${ }^{62}$ Although the spin localisation on the chain was not addressed, it is likely to be significant on the basis of the behaviour of monometallic species (oxidative coupling) and of the composition of the parent frontier orbitals. For example, with the paramagnetic $\left[\mathrm{I}(\mathrm{dmpe})_{2} \mathrm{Mn}^{\mathrm{II}}-\right.$ $\left.\mathrm{C} \equiv \mathrm{C}-\mathrm{C} \equiv \mathrm{C}-\mathrm{Mn}^{\mathrm{II}}(\mathrm{dmpe})_{2} \mathrm{I}\right](\mathbf{2 0})$, the two single electrons occupy quasi-generated orthogonal $\pi$-orbitals which extend significantly over the $\mathrm{C}_{4}$ chain and the manganese centres with parallel spins. Thus, the oxidized species that show fast delocalisation of the single electron on NMR and EPR time scales, slow on the IR time scale, probably displays spin density on the chains.

Platinum complexes trans $-\left[\left(\mathrm{C}_{6} \mathrm{~F}_{5}\right)\left(\mathrm{p}-\mathrm{tol}_{3} \mathrm{P}\right)_{2} \mathrm{Pt}(\mathrm{C} \equiv \mathrm{C})_{n} \mathrm{Pt}\right.$ $\left[\left(\mathrm{C}_{6} \mathrm{~F}_{5}\right)\left(\mathrm{p}-\mathrm{tol}_{3} \mathrm{P}\right)_{2}\right](\mathbf{2 1} ; n=2,4,6,8)$ have been obtained and studied using cyclic voltammetry. ${ }^{63}$ Even though the oxidized states have not been isolated and studied, cyclic voltammograms indicate the decrease of reversibility with length. The initially formed radical cations are proposed to undergo interchain coupling and/or solvent atom transfer reactions, a fact enforced by the observation of chain-chain coupling with analogous tetrametallic complexes bearing two parallel $\mathrm{Pt}-\mathrm{C} \equiv \mathrm{C}-\mathrm{Pt}$ linkages. As with the rhenium analogues, these observations also suggest a significant spin density on the chain that increases with length.

Few bis-carbyne complexes are known in contrast to previous systems. For tungsten complexes, purely metal centred oxidations were reported. ${ }^{64}$ For example, it was proposed that with $\mathrm{Cl}(\mathrm{dmpe})_{2} \mathrm{~W} \equiv \mathrm{C}-\mathrm{C} \equiv \mathrm{W}(\mathrm{dmpe})_{2} \mathrm{Cl}$ (22), two sequential oneelectron oxidations produce $\left(\mathrm{d}_{\mathrm{xy}}\right)^{2}-\left(\mathrm{d}_{\mathrm{xy}}\right)^{1}$ and $\left(\mathrm{d}_{\mathrm{xy}}\right)^{1}-\left(\mathrm{d}_{\mathrm{xy}}\right)^{1}$ congeners. Nevertheless, this was assumed on the basis of the electronic structure of the neutral compound. Furthermore, considering the presence of $\mathrm{W}-\mathrm{C} \pi$ orbitals in the bunch of the HOMOs and the relaxation occurring upon oxidation, one cannot refute the implication of the carbon bridge in the redox processes. Indeed, for $\left[\mathrm{I}(\mathrm{dppe})_{2} \mathrm{~W} \equiv \mathrm{C}-\mathrm{C} \equiv \mathrm{C}-\mathrm{C} \equiv \mathrm{W}(\mathrm{dppe})(\mathrm{CO})_{2} \mathrm{I}\right]$, Raman spectroscopy reflects a noticeable change in the $\mathrm{C}_{4}$ bridge upon oxidation and the EPR results reveal a smaller anisotropy of the signal than in related compounds. ${ }^{64 c}$

Finally, concerning cumulenic species, the studies are scarce. Only the reductions of two ruthenium bis-allenylidene complexes including a phenyl or a bis-anthracenyl linker were reported. ${ }^{65}$ In those reduced species, the single electron is proposed to be basically centred on the ligand framework, even if the presence of some metallic character is detected. For example, with trans $-\left[\mathrm{Cl}(\mathrm{dppe})_{2} \mathrm{Ru}=\mathrm{C}=\mathrm{C}=\mathrm{CPh}-1,4-\mathrm{C}_{6} \mathrm{H}_{4}\right.$ $\left.\mathrm{PhC}=\mathrm{C}=\mathrm{C}=\mathrm{RuCl}(\mathrm{dppe})_{2}\right][\mathrm{OTf}]_{2}$ (23), the first reduction leads to the observation of a broad signal with $g=2.0244$ at $298 \mathrm{~K}$, and observed shoulders may indicate some transition metal contribution resulting in the coupling of the free electron with the ${ }^{99} \mathrm{Ru}$ and ${ }^{101} \mathrm{Ru}$ isotopes.

\section{What about complexes bearing more than two metallic centres?}

Systems with more than two metal units can be either star-shaped or in a linear arrangement. Quite a few studies have been reported on star-shaped molecules with full investigations of the first oxi- 
dized/reduced state owing to overlapping of several redox events. As an interesting example, the tetrakis(4-styryl)ethene (bridged tetraruthenium complex $(E, E, E, E)-\left[\left\{\left(\mathrm{P}^{i} \mathrm{Pr}_{3}\right)_{2}(\mathrm{CO}) \mathrm{ClRu}\right\}_{4}\left\{\mu_{4}-\right.\right.$ $\left.\left.\left(\mathrm{CH}=\mathrm{CHC}_{6}-\mathrm{H}_{4}\right)_{4}(\mathrm{C}=\mathrm{C})\right\}\right]$ (24) undergoes four consecutive oxidations at low potentials (Chart 3). ${ }^{66}$ The ligand-dominated nature of these processes is demonstrated by spectroscopic and quantumchemical investigations. In particular, the EPR spectra obtained at $110 \mathrm{~K}$ with the mono oxidized species displays a rhombic splitting of the $g$ tensor with $<g>=2.040$ and $\Delta g=0.058$. The HOMO of the neutral complex is delocalised across the $\pi$ system of the bridging ligand with small contributions of the ruthenium atoms $(\sim 10 \%)$. The closely lying HOMO-1, HOMO-2, and HOMO-3 orbitals have negligible contributions from the central ethylene group and are mainly composed of the styryl $\pi$ orbitals with overall $\mathrm{Ru}$ contributions of 28,30 , and $36 \%$, respectively. Unfortunately, the spin densities of the cation were not reported. However, these elements tend to describe this species as a metal-stabilized but mainly ligand-centred paramagnetic species, as it is also the case for other $\pi$-conjugated vinyl ruthenium complexes described above.

Surprisingly, experimental studies on linear organometallic carbon-rich systems with more than two identical redoxactive metallic fragments also remain particularly scarce, probably for synthetic reasons, and restricted. Indeed, several examples have been reported with trimetallic species of ruthenium acetylides of the type $\mathrm{RuL}_{2}(\mathrm{~L}=$ dppe, dmpe and/or depe), but these studies have been limited to electrochemical investigations. ${ }^{57,67}$ Nevertheless, large chain participation was expected by comparison with bimetallic analogues. On the basis of the earlier studies on "W"-shaped molecules using the fragment $\left[\mathrm{RuCl}(\mathrm{dppe})_{2}\right]^{+}$, we realized two $28 \AA$ long highly conjugated molecular wires with three similar metal centres spanned by two odd-numbered $\mathrm{C} 7 \pi$-conjugated chains trans-[Cl(dppe) $)_{2} \mathrm{Ru}=\mathrm{C}=\mathrm{C}=(\mathrm{Ph}) \mathrm{C}-\mathrm{CH}=\left(\mathrm{CH}_{3}\right) \mathrm{C}-\mathrm{C} \equiv \mathrm{C}-(\mathrm{X})_{2} \mathrm{Ru}-\mathrm{C} \equiv \mathrm{C}-$ $\left.\mathrm{C}\left(\mathrm{CH}_{3}\right)=\mathrm{CH}-\mathrm{C}(\mathrm{Ph})=\mathrm{C}=\mathrm{C}=\mathrm{Ru}(\mathrm{dppe})_{2} \mathrm{Cl}\right](\mathrm{OTf})_{2}(25 ; \mathrm{X}=$ dppe, $\mathrm{dppm}$ ), in order to answer the fascinating question of whether these large size carbon-rich spacers can facilitate electron transfer over more than two metal centres of the same type, and a priori preventing single electron trapping on one part of the structure. ${ }^{68}$ These complexes display five well-separated redox processes, and the complete studies of the oxidized and reduced states using a combination of spectroscopic (UV-vis-NIR-IR and EPR) and theoretical techniques were achieved. In particular, careful EPR spectroscopy experiments and DFT calculations, unprecedented for such extended systems, turned out to be particularly valuable tools. For example, upon one-electron reduction of the complex with the central dppe ligands, an EPR spectrum is observed at room temperature, which consists of a single line with $\Delta H \mathrm{pp}=20 \mathrm{G}$ and $g=2.0040$, and that suggests a ligand-centered paramagnetic species. DFT calculations rationalize this with the single electron delocalisation over the two carbon chains through the central metal atom to an extent driven by the rotations within and between the chains. In the fully delocalised arrangement, the reduced radical species present a strongly polarized spin density quasi exclusively localised on the odd numbered carbon atoms of the conjugated skeleton (Fig. 2). In contrast, the first oxidation processes strongly involve both the metal atoms and the bridging ligands. With the mono oxidized species, the EPR spectrum shows a slightly anisotropic rhombic $g$-tensor with $\langle g\rangle=2.0147$ and $\Delta g=0.0025$ at $4 \mathrm{~K}$ for the dppm complex. The DFT investigations reveal that the mono-oxidized system presents a spin density uniformly distributed between the metal atoms and the carbon atoms of the chains that are hardly affected upon rotation. A noticeable atomic spin density is found on the terminal chlorine atoms (Fig. 2).

Very recently, the group of Ren reported the synthesis of an elegant complex, the trans- $\left[\mathrm{Ru}_{2}(\mathrm{diMeOap})_{4}(\mathrm{C} \equiv \mathrm{C})_{2}\right.$ $\mathrm{Ru}_{2}(\mathrm{DMBA})_{4}-\left(\mathrm{C} \equiv \mathrm{C}_{2} \mathrm{Ru}_{2}(\mathrm{diMeOap})_{4}\right] \quad\left(\right.$ 26) $\quad\left(\mathrm{DMBA}=N, N^{\prime}-\right.$ dimethylbenzamidinate) in which three di-ruthenium units are connected by two butadiynyl chains. Unfortunately the oxidized species were not stable enough to be investigated experimentally, ${ }^{69}$ but the theoretical results provided in this study allow the authors to conclude that the unpaired electrons in $\mathbf{2 6}$ are probably delocalised from the terminal $\mathrm{Ru}_{2}$ units to the central one, the conjugated ligand playing an important role.

Finally, it is worth mentioning that another elegant linear redox active hetero-tetrametallic complex $\left\{[\mathrm{Fe}]-(\mathrm{C} \equiv \mathrm{C})_{2}-[\mathrm{W}] \equiv \mathrm{C}-\right.$ $\left.\mathrm{C} \equiv \mathrm{C}-\mathrm{C} \equiv[\mathrm{W}]-(\mathrm{C} \equiv \mathrm{C})_{2}-[\mathrm{Fe}]\right\}(27)$ was recently obtained by Berke et $a l .{ }^{70}$ The first oxidized complex displays an isotropic sharp EPR spectra at room temperature with " $g=2$ " which indicates


26


27

Chart 3 


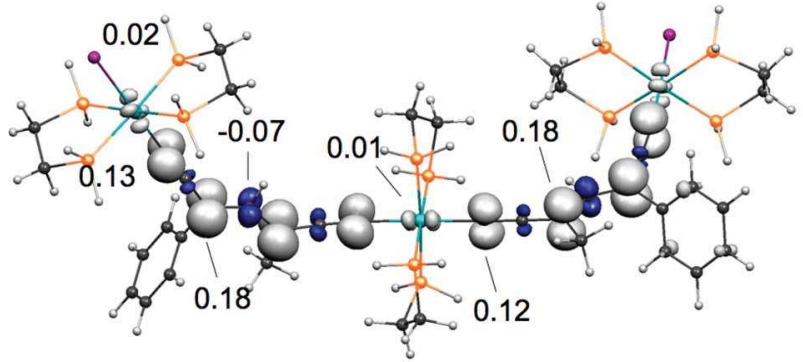

25- $\mathrm{H}^{+}$

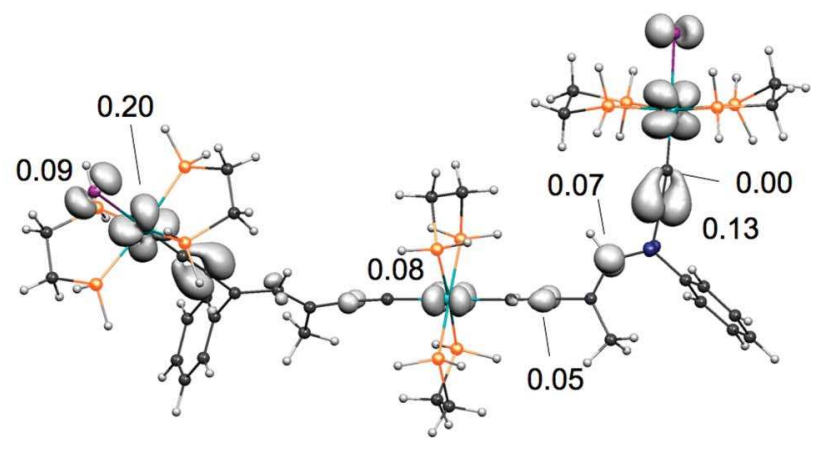

$25-\mathrm{H}^{3+}$

Fig. 2 Spin densities calculated for the simplified models (with dpe ligands) of $25-\mathrm{H}^{\mathrm{n}+}$, for $n=1$ and $n=3$. Iso-contours $= \pm 0.0025$ e bohr ${ }^{-3}$.

a limited participation of the iron centres and probably a significant participation of the chain to the redox event. This makes the interpretation of this oxidized species as a mixedvalent complex and the use of Hush formalism to illustrate the optical electron transfer between the iron centres as proposed unlikely.

\section{Consequences and applications}

In this last part of this paper, we now present some examples of applications for this type of carbon-rich complexes that take advantage of their peculiar electronic structures highlighted above. Indeed, different studies directed toward various applications in molecular electronics showed that the strong coupling of the metals and ligands in redox-active carbon-rich metal complexes leads to interesting physical properties. We have selected here some representative examples.

The first straightforward application is the achievement of accurate wires as the ultimate tiny building blocks for electronic circuits (i.e. wires bearing functional linking groups to connect to electrodes). More generally, the use of a single molecule would be an enormous step in terms of size reduction. Several studies have been performed to probe the electrical conductivity of carbon rich complexes. It is worth mentioning that the first study by Mayor and co-workers ${ }^{71}$ showed that the non-redox active trans-platinum complex AcS- $p-\mathrm{C}_{6} \mathrm{H}_{4}-\mathrm{C} \equiv \mathrm{C}-\mathrm{Pt}\left(\mathrm{Ph}_{3}\right)_{2}-\mathrm{C} \equiv \mathrm{C}-p-\mathrm{C}_{6} \mathrm{H}_{4}-\mathrm{SAc}$ is a single molecule insulator when integrated in a break-junction com- pared to related organic analogues. The increased resistance was attributed to the pure $\sigma$ character of the $\mathrm{Pt}-\mathrm{C}(\mathrm{sp})$ bond that separates the molecular rod into two independent conjugated systems. Nevertheless, using a cross-wire junction technique, it was also reported that with trans $-\left[\mathrm{PtL}_{2}\left(\mathrm{C} \equiv \mathrm{C}-\mathrm{C}_{6} \mathrm{H}_{4} \mathrm{SAc}-4\right)_{2}\right](\mathrm{L}=$ $\left.\mathrm{PCy}_{3}, \mathrm{PBu}_{3}, \mathrm{PPh}_{3}, \mathrm{P}(\mathrm{OEt})_{3}, \mathrm{P}(\mathrm{OPh})_{3}\right)$ complexes, the incorporation of $\mathrm{Pt}$ atom in $\pi$-conjugated molecular wires does not adversely affect charge transport compared to all-carbon $\pi$-conjugated molecular wires. ${ }^{72}$ The current-voltage $(I-V)$ characteristics also showed no ancillary ligand effect, and it was concluded that the tunnelling efficiency across the molecule is the determining factor for conduction.

In sharp contrast with these results, investigation of self assembled monolayers (SAMs) of the $\left[\mathrm{Ru}_{2}(\mathrm{ap})_{4}\left(\mathrm{C} \equiv \mathrm{C}-\mathrm{C}_{6} \mathrm{H}_{4}\right)_{2}-4-\right.$ S-] (28) complex (Chart 4) embedded in undecanethiol ${ }^{73}$ using the STM technique, showed that the contact conductance of the conductor-molecule coupling is at least $15 \%$ larger than that of the oligo(phenylene ethynylene) (OPE) molecule of comparable length. The enhancement of conductance clearly demonstrated that the insertion of the $\mathrm{Ru}_{2}(\mathrm{ap})_{4}$ unit with a small energy gap (ca. $1.28 \mathrm{eV}$ from $\mathrm{CV}$ measurement) into an organic conjugated backbone brings a substantial improvement of wire characteristics. Further studies of electronic transport through selfassembling of related diruthenium(III) tetra(2-anilinopyridinate)di(4-thiolphenylethynyl) trans- $\left[\mathrm{Ru}_{2}(\operatorname{ap})_{4}\left(\left(\mathrm{C} \equiv \mathrm{CC}_{6} \mathrm{H}_{4}\right)_{n} \mathrm{~S}-\right)_{2}\right] \quad(n=$ $1,2)$ molecules in nanogap molecular junctions ${ }^{74}$ confirmed that devices employing redox-active molecules, in which the

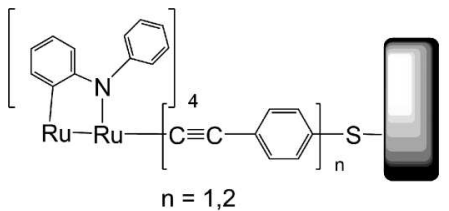

28

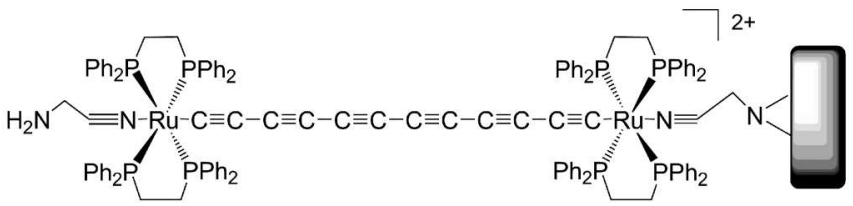

30

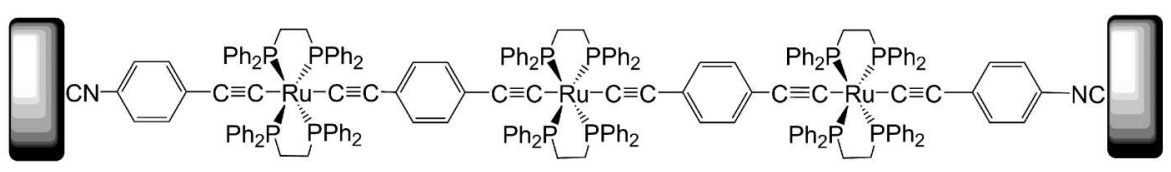

29

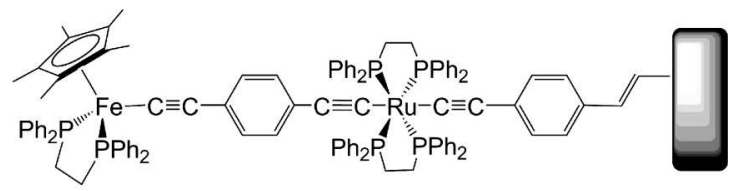

31

Chart 4 
molecular levels are close to the electrode Fermi level, allow resonant tunnelling, along with observation of hysteresis in $I-V$ traces possibly due to charge storage in the molecules. These features are interesting for memory or chemical sensing applications. The related donor-acceptor (D- $\pi-\mathrm{A})$ complex trans(4- $\left.\mathrm{Me}_{2} \mathrm{NC}_{6} \mathrm{H}_{4} \mathrm{C} \equiv \mathrm{C}\right) \mathrm{Ru}_{2}(\mathrm{DMBA})_{4}-\left(\mathrm{C} \equiv \mathrm{CC}_{6} \mathrm{H}_{4}-2,5-(\mathrm{OMe})_{2}-4-\right.$ $\mathrm{NO}_{2}$ ) was also proposed as a molecular rectifier. ${ }^{75}$

Using conducting probe atomic force microscopy (CP-AFM) and crossed-wire (X-wire) junctions, we probed the electrical transport behaviour of another series of ruthenium redox-active conjugated molecular wires as a function of temperature and molecular length. ${ }^{76}$ The wires consist of covalently coupled ruthenium(II) bis( $\sigma$-arylacetylide) $\mathrm{CN}-p-\mathrm{C}_{6} \mathrm{H}_{4}-\mathrm{C} \equiv \mathrm{C}-(\mathrm{Ru}-\mathrm{C} \equiv \mathrm{C}$ $\left.p-\mathrm{C}_{6} \mathrm{H}_{4}\right)_{n}-\mathrm{NC}(n=1-3)$ complexes and range in length from 2.4 to $4.9 \mathrm{~nm}$. At room temperature, a very weak dependence of the wire resistance with molecular length $(\beta=0.9 / \mathrm{nm})$ was found, consistent with a high degree of electronic coupling along the molecular backbone. In low temperature $(5 \mathrm{~K})$ experiments, Coulomb blockade-like behaviour (charge injection) was observed in junctions incorporating trimetallic species $\mathbf{2 9}$ and direct tunnelling is found to be the dominant transport mechanism in the others junctions (probably via through-bond tunnelling, i.e., superexchange). With a similar monometallic ruthenium(II) bis(arylacetylide) complex-based molecular wire functionalized with thiolacetyl alligator clips at both ends, STM and CP-AFM measurements confirm the lower electronic decay constant as well as the higher conductance compared to organic analogues. This was attributed to the lower band gap between the HOMO and the gold surface Fermi level, expected to be beneficial for the longrange. ${ }^{77}$

Fehlner and co-workers proposed another application for this type of "mixed-valent" complexes in a non-transistorbased paradigm for molecular electronics with an external electric field control of the position of an electron. ${ }^{78}$ This Quantum Cellular Automata (QCA) paradigm transmits binary information utilizing electric field coupled cells rather than current flow. A prototype of a biased two-dot molecular QCA was realised with the ruthenium complex $\left[\left(\mathrm{H}_{2} \mathrm{NCH}_{2} \mathrm{CH}_{2} \mathrm{C} \equiv \mathrm{N}\right)\right.$ (dppe $\left.)_{2} \mathrm{Ru}(\mathrm{C} \equiv \mathrm{C})_{6} \mathrm{Ru}(\text { dppe })_{2}\left(\mathrm{~N} \equiv \mathrm{CCH}_{2} \mathrm{CH}_{2}-\mathrm{NH}_{2}\right)\right]\left[\mathrm{PF}_{6}\right]_{2}$ functionalized for binding to a silicon substrate. Measurement of the ac capacitance of the film of the oxidized species as a function of voltage across the film with a pulse-counter pulse technique demonstrates controlled electric field generation of the two stable forms differing in the spatial location of one electron by moving the electron between the two "metals" (or sides), which is switching.

Some authors also investigated the possibility of a redox modulation of the NLO properties with various species. For example, mononuclear electron-rich organoiron(II) $\left[\left(\eta^{2}-\right.\right.$ dppe $)\left(\eta^{5}-\right.$ $\left.\left.\mathrm{C}_{5} \mathrm{Me}_{5}\right) \mathrm{Fe}-\mathrm{C} \equiv \mathrm{C}-1,4-\left(\mathrm{C}_{6} \mathrm{H}_{4}\right) \mathrm{X}\right](\mathbf{1 - X})$ compounds show significant quadratic polarizabilities that are strongly decreased in the corresponding cationic $\mathrm{Fe}(\mathrm{III})$ parents. ${ }^{79}$ Bimetallic mixed iron and ruthenium acetylides such as $\left[\left(\eta^{2}-\mathrm{dppe}\right)\left(\eta^{5}-\mathrm{C}_{5} \mathrm{Me}_{5}\right) \mathrm{Fe}-\mathrm{C} \equiv \mathrm{C}\right.$ 1,4- $\left(\mathrm{C}_{6} \mathrm{H}_{4}\right)-\mathrm{C} \equiv \mathrm{C}-\mathrm{Ru}(\mathrm{dppe})_{2} \mathrm{Cl}$ ] showed redox switching of cubic NLO properties up to three states (nonlinearity "off", and two forms of nonlinearity "on", namely, two-photon absorber and saturable absorber), with "switch on" of optical transitions at long wavelength, and linear electrochromic effects. ${ }^{38 a, 80}$ It has also been shown that modified electron-rich dinuclear acetylide complexes
31 can be grafted onto hydrogenated silicon surfaces and exhibit facile stepwise electron transfer between the bound metal centres and the silicon surface through the interfacial $\mathrm{Si}-\mathrm{C}$ bond, paving the way to devices. ${ }^{81}$

Concerning luminescence features, Yam, Lapinte and coworkers reported the synthesis of a heterobimetallic iron(II)rhenium(I) complex, $\left[\operatorname{Re}(\right.$ bpy $)(\mathrm{CO})_{3}\left(\mathrm{C} \equiv \mathrm{C}-\mathrm{C}_{6} \mathrm{H}_{4}-\mathrm{C} \equiv \mathrm{C}\right) \mathrm{Fe}\left(\eta^{5}-\right.$ $\mathrm{C}_{5} \mathrm{Me}_{5}$ )-(dppe)], a redox "switch" capable of switching on and off its triplet photoluminescence. The presence of low-lying MLCT and LF excited states of the iron moiety would readily quench the ${ }^{3}$ MLCT emission of the rhenium bipyridyl core, either by nonradiative interstate crossing, energy transfer, or electron transfer processes. After one electron oxidation, the unpaired electron is delocalised over the iron and the carbon linker with a bit more than half of the spin density $\left(0.58 \mathrm{e}^{-}\right)$found on the iron centre, and the rest on the carbon chain. This electron deficient moiety species is not a good electron donor and, thus, no reductive electron transfer quenching can occur. The luminescence of the rhenium core is restored. ${ }^{82}$

In the search for multiple controllable properties in a single component system, our group was looking for new systems displaying unique synergetic properties with an accurate combination of a metal complex and of a photochromic unit. ${ }^{83}$ Dithienylethene (DTE) is an ideal photochromic molecule that undergoes reversible interconversion between a non-conjugated open form and a $\pi$-conjugated closed form to achieve gating of several properties. The perturbation of the DTE system by the ruthenium carbonrich system, and vice-versa, was used to reach a light- and electrotriggered multifunctional switch $\left[\mathrm{ClRu}(\mathrm{dppe})_{2}-\mathrm{C} \equiv \mathrm{C}-\mathrm{DTE}-\mathrm{C} \equiv \mathrm{C}-\right.$ (dppe) $\left.{ }_{2} \mathrm{RuCl}\right]$ (32) featuring multicolor electrochromism, and an unprecedented electrocyclisation at remarkably low voltage (Scheme 5). This latter property is the illustration of the peculiar electronic properties of the ruthenium complexes. Indeed, in the doubly oxidized state, the strong electron delocalisation on the carbon-rich ligand, including the thiophene rings, leads to a DTE closing via radical coupling (triplet state). This is fully supported by theoretical DFT investigations (Fig. 3).

A similar electrochemical closing was observed for the related ruthenium species $\mathbf{3 3}$ with direct $\sigma$ bonds between the metals and the thiophene units of the DTE,$^{84}$ or via an acetylene ${ }^{85}(\mathbf{3 4})$ or a viny ${ }^{86}$ linker (35) (Chart 5). This electrocyclisation is probably attributable to the same origin. The case of the iron $\mathrm{Fe}\left(\eta^{5}\right.$ $\mathrm{C}_{5} \mathrm{Me}_{5}$ )(dppe) analogues $\mathbf{3 6}$ and $\mathbf{3 7}$ are particularly interesting. For the complex 36, displaying a direct $\sigma$ bonds between the metals and the thienyl units, the closing is observed whereas it is not when acetylide spacers are present in 37. DFT calculations on the doubly oxidized open form of $\mathbf{3 4}$ and $\mathbf{3 7}$ shows that the spin density is almost twice as important on the carbon atoms of interest for $\mathrm{M}=\mathrm{Ru}$ than for $\mathrm{M}=\mathrm{Fe} \cdot{ }^{87}$ This is consistent with our previous results and with the usual greater ability of ruthenium complexes to accommodate the single electron on carbon-rich ligands (vide supra). Nevertheless, the iron species display an almost isotropic EPR spectrum at $78 \mathrm{~K}$, showing the significant participation of the chain in the redox processes. Finally, it is worth emphasising that longer conjugated bridges lead to "dilution" of the spins and play against closing as revealed by (i) the behaviour of the two iron species mentioned above and (ii) the fact that an additional phenylethynyl unit prevents electrochemical closing in the ruthenium species $388^{88}$ 


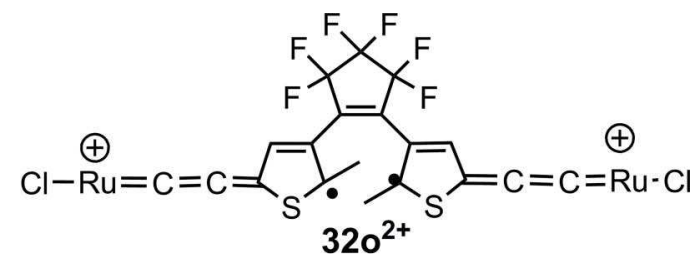

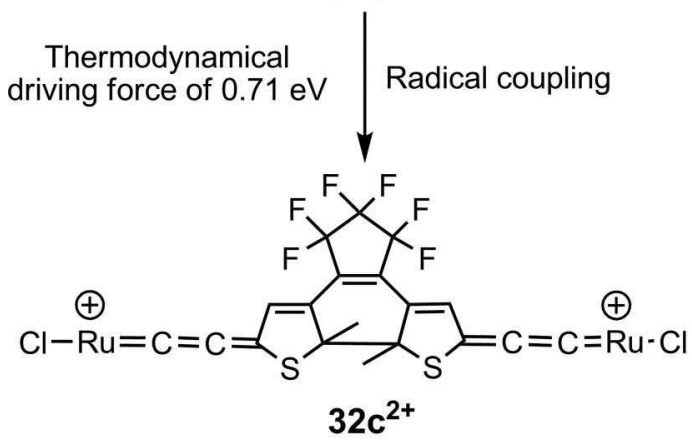

(a)

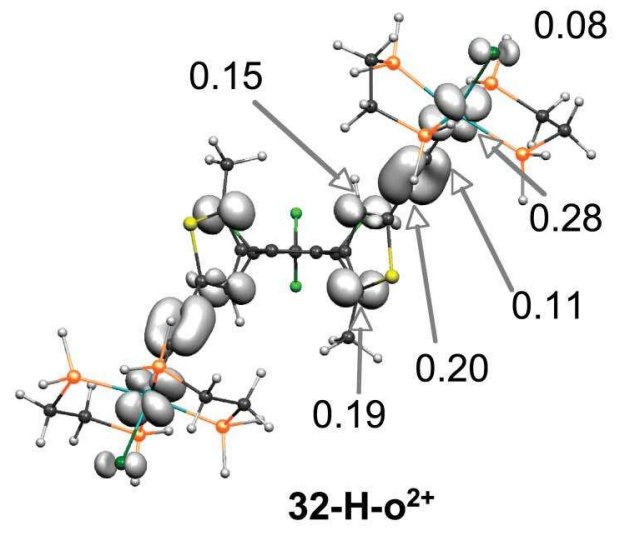

(b)

Fig. 3 (a) Proposed closing mechanism. (b) Top view of calculated isosurface $\left(0.0045 \mathrm{e} \mathrm{bohr}^{-3}\right)$, and atomic spin densities of the modelled complex 32-H-o ${ }^{2+}$ (triplet state). The dppe ligands of $\mathbf{3 2 0}$ were replaced with dpe.

\section{Conclusion}

The different experimental and theoretical studies on carbon-rich complexes reveal that genuine metal oxidations are not observed, and that the level of implication of the carbon rich ligand in the redox processes is very sensitive to the nature of (i) the metal(s), (ii) the ancillary ligand, and (iii) the carbon-rich (bridging) ligand. Furthermore, this participation is frequently found to be major. Consequently, the general denomination $\mathbf{M}^{(n+1)}$ or $\mathbf{M}^{(n-1)}$ often used for an oxidized or reduced species and that gives the picture that only the metal density is affected, is questionable and might be misleading. Moreover, for most of the polymetallic species discussed herein, even if their oxidation or reduction states are formally mixed-valent systems, the electronic transition modelling developed from classical theories and the associated language are not appropriate due notably to splitting of the $\mathrm{d}$ orbitals and/or ligand delocalisation. The comparisons between
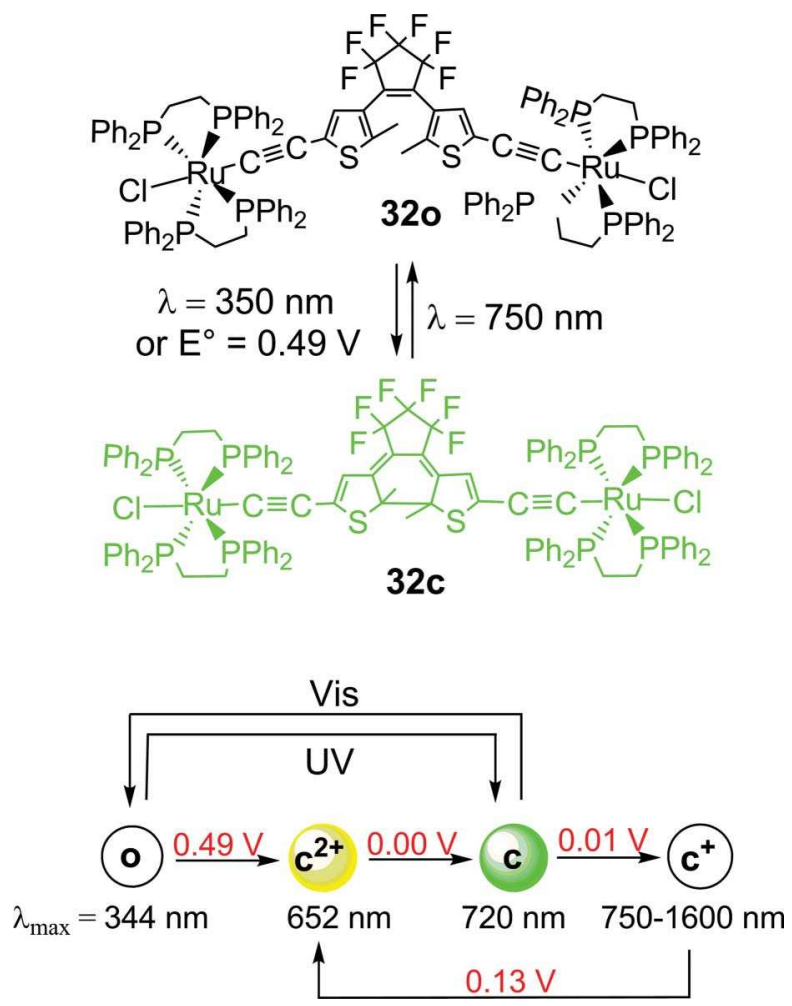

Scheme 5<smiles>[X]c1cc(C(C(F)(F)F)C(F)(F)C(F)(F)F)c(C(C)C)s1</smiles>



Chart 5

different compounds of the electronic coupling established on these bases are thus risky. Experimental tools, such as EPR spectroscopy, and quantum mechanics calculations are, in this domain, really helpful in appreciating the participation of the ligands in the redox processes and the spin delocalisation in the resultant oxidized/reduced species. Moreover, the recent progress of quantum mechanics (with DFT: meta-hybrid functionals, longrange corrected functionals, relativistic effects, correction of the self-interaction error; ab initio molecular dynamics; solvation ...) associated with the increasing capacities of supercomputers provide more and more quantitative results.

Therefore, systems whose properties cannot be correctly rationalized by actual theories are precious objects for theoretical 
studies and physical measurements. The complementarities of the experimental and theoretical approaches will definitely help in improving the level of knowledge in this domain., ${ }^{3 b, 14} \mathrm{We}$ do believe that organometallic systems containing carbon-rich conjugated bridges are particularly well-suited for improving this knowledge particularly because, as illustrated above, their electronic properties can be smoothly tuned by slight structural modifications (ancillary ligands, bridging ligands, metal atoms, geometrical arrangements) providing an infinite number of objects for research. In addition, these metal complexes potentially offer numerous addressable functionalities in one molecular component, owing to these unique easily tuneable electronic properties. Therefore, they are also well-suited systems to bring molecular electronics knowledge to a further stage of development.

\section{Acknowledgements}

The authors wish to thank Dr Jean-François Halet for helpful discussions.

\section{References}

1 A. Aviram and M. A. Ratner, Chem. Phys. Lett., 1974, 29, 277; R. L. Carroll and C. B. Gorman, Angew. Chem., Int. Ed., 2002, 41, 437; J. A. Nitzan and M. A. Ratner, Science, 2003, 300, 1384; R. L. McCreery, Chem. Mater., 2004, 16, 4477; C. Joachim and M. A. Ratner, Proc. Natl. Acad. Sci. U. S. A., 2005, 102, 8801; R. M. Metzger, J. Mater. Chem., 2008, 18, 4364; S. H. Choi, B.-S. Kim and C. D. Frisbie, Science, 2008, 320, 1382; V. Balzani, A. Credi, and M. Venturi, in Molecular Devices and Machines. Concepts and Perspectives for the Nanoword, Wiley-VCH, Weinheim, 2nd edn, 2008, and references therein.

2 J.-M. Lehn, in Supramolecular Chemistry: Concepts and Perspectives, Wiley-VCH, Weinheim, 1995.

3 (a) K. D. Demadis, C. M. Harshorn and T. J. Meyer, Chem. Rev., 2001, 101, 2655; (b) P. Chen and T. J. Meyer, Chem. Rev., 1998, 98, 1439; (c) D. M. D'Alessandro and R. F. Keene, Chem. Rev., 2006, 106, 2270; (d) F. Paul and C. Lapinte, Coord. Chem. Rev., 1998, 178-180, 431; (e) P. Aguirre-Etchevery and D. O'Hare, Chem. Rev., 2010, 110, 4839; (f) P. J. Low and N. J. Brown, J. Cluster Sci., 2010, 21, 235, DOI: $10.1007 / \mathrm{s} 10876-010-0328-4 ;(g)$ A. Ceccon, S. Santi, L. Oian and A. Bisello, Coord. Chem. Rev., 2004, 248, 683; $(h)$ M. H. Chisholm and N. J. Patmoore, Acc. Chem. Res., 2007, 40, 19; (i) J.-P. Launay, Chem. Soc. Rev., 2001, 30, 386.

4 S. F. Nelsen, Chem.-Eur. J., 2000, 6, 581; D.-L. Sun, V. Rosokha and J. K. Kochi, J. Am. Chem. Soc., 2003, 125, 15950; S. Barlow, C. Risko, S.-J. Chung, N. M. Tucker, V. Coropceanu, S. C. Jones, Z. Levi, J.-L. Brédas and S. R. Marder, J. Am. Chem. Soc., 2005, 127, 16900; D. R. Kattnig, B. Mladenova, G. Grampp, C. Kaiser, A. Heckmann and C. Lambert, J. Phys. Chem. C, 2009, 113, 2983and references therein; J. Bonvoisin, J.-P. Launay, W. Verbouwe, M. Van, der Auweraer and F. C. De Schryver, J. Phys. Chem., 1996, 100, 17079.

5 D. Astruc, in Electron Transfer and Radical Processes in TransitionMetal Chemistry, VCH-Publishers, Inc., New York, 1995.

6 W. Kaim and G. K. Lahiri, Angew. Chem., Int. Ed., 2007, 46, 1778; M. D. Ward and J. A. McClaverty, J. Chem. Soc., Dalton Trans., 2002, 275; S. Záliš, R. F. Winter and W. Kaim, Coord. Chem. Rev., 2010, 254, 1383.

7 C. Lambert, S. Althor and J. Schelter, J. Phys. Chem. A, 2004, 108, 6474.

8 C. E. B. Evans, M. L. Naklicki, A. R. Rezvani, C. A. White, V. V. Kondratiev and R. J. Crutchley, J. Am. Chem. Soc., 1998, 120, 13096.

9 P. Day, N. S. Hush and R. J. H. Clark, Philos. Trans. R. Soc. London, Ser. A, 2008, 366, 5 .

10 R. A. Marcus, Annu. Rev. Phys. Chem., 1964, 15, 155.

11 R. S. Mulliken, J. Am. Chem. Soc., 1952, 64, 811; R. S. Mulliken, and W. B. Person, in Molecular complexes, Wiley, New York, 1969; N. S. Hush, Prog. Inorg. Chem., 1967, 8, 391; N. S. Hush, Electrochim. Acta, 1968, 13, 1005.
12 Robin and Day's classification established that (1) Class I systems correspond to a trapped valence on one of the two sites; (2) If the 'mixed-valent' atoms are completely undistinguishable the compound is classified as class III with a genuine non-integral valence; (3) Class II lies between the two previous cases with an accessible thermal electron transfer and the presence of an intervalence transfer optical transition, see: M. B. Robin and P. Day, Adv. Inorg. Chem., 1967, 10, 247.

13 D. M. D'Alessandro and F. R. Keene, Chem. Soc. Rev., 2006, 35, 424.

14 J. R. Reimers, B. B. Wallace and N. S. Hush, Philos. Trans. R. Soc. London, Ser. A, 2008, 366, 15.

$15 \mathrm{rab}=|(\mathrm{mb}-\mathrm{ma}) / \mathrm{e}|$; ma and $\mathrm{mb}$ are the dipole moments of the diabatic states $a$ and $b$, respectively.

16 J. T. Hupp, Y. Dong, R. L. Blackbourn and H. Lu, J. Phys. Chem., 1993, 97, 3278; G. U. Bublitz, W. M. Laidlaw, R. G. Denning and S. G. Boxer, J. Am. Chem. Soc., 1998, 120, 6068.

17 R. J. Cave and M. D. Newton, Chem. Phys. Lett., 1996, 249, 15.

18 H. M. McConnell, J. Chem. Phys., 1961, 35, 508; M. A. Ratner, J. Phys. Chem., 1990, 94, 4877; S. D. Glover, J. C. Goeltz, B. J. Lear and C. P. Kubiak, Coord. Chem. Rev., 2010, 254, 331.

19 S. F. Nelsen, R. F. Ismagilov and D. R. Powell, J. Am. Chem. Soc., 1998, 120, 1924; A. El-ghayoury, A. Harriman, A. Khatyr and R. Ziessel, J. Phys. Chem. A, 2000, 104, 1512; S. Fraysse, C. Coudret and J.-P. Launay, J. Am. Chem. Soc., 2003, 125, 5888; C. Lambert, S. Amthor and J. Schelter, J. Phys. Chem. A, 2004, 108, 6474; M. Fabre, J. Jaud, M. Hliwa, J.-P. Launay and J. Bonvoisin, Inorg. Chem., 2006, 45, 9332-9345; F. de Montiny, G. Argouarch, K. Costuas, J.-F. Halet, L. Toupet and C. Lapinte, Organometallics, 2005, 24, 4558; M. Fabre and J. Bonvoisin, J. Am. Chem. Soc., 2007, 129, 1434; M. H. Chisholm, J. S. D'Achioli, C. M. Hadad and N. J. Patmore, Inorg. Chem., 2006, 45, 11035.

20 B. S. Brunschwig, C. Creutz and N. Sutin, Chem. Soc. Rev., 2002, 31, 168; J.-P. Launay, C. Coudret and C. Hortholary, J. Phys. Chem. B, $2007,111,6788$.

21 (a) J. J. Conception, D. M. Dattelbaum, T. J. Meyer and R. C. Rocha, Philos. Trans. R. Soc. London, Ser. A, 2008, 366, 163; (b) R. G. Rocha, F. N. Rein, H. Jude, A. P. Scheve, J. J. Conception and T. J. Meyer, Angew. Chem., Int. Ed., 2008, 47, 503.

22 Other parameters should be taken into account as well as temperature dependence, particularly because of vibrational evolution and vibronic coupling, interaction with the electrolyte, ion-pairing possibilities or polarisability effects.

23 (a) A. Zheludev, V. Barone, M. Bonnet, B. Delley, A. Grand, E. Ressouche, P. Rey, R. Subra and J. Schweizer, J. Am. Chem. Soc., 1994, 116, 2019; (b) A. S. Wills, E. Lelievre-Berna, F. Tasset, J. Schweizer and R. Ballou, Phys. B, 2005, 356, 254; (c) J. Luzón, J. Campo, F. Palacio, G. J. McIntyre and A. Millán, Phys. Rev. B: Condens. Matter Mater. Phys., 2008, 78, 054414; (d) E. Lelièvre-Berna, A. S. Wills, E. BourgeatLami, A. Dee, T. Hansen, P. F. Henry, A. Poole, M. Thomas, X. Tonon, J. Torregrossa, K. Andersen, F. Bordenave, D. Jullien, P. Mouveau, B. Guérard and G. Manzin, Meas. Sci. Technol., 2010, 21, 055106.

24 H. M. McConnell, J. Chem. Phys., 1961, 35, 508.

25 DFT results were indeed shown to be in good agreement with the experimental spin-densities, see ref. $23 \mathrm{a}, \mathrm{c}$.

26 M. Reiher, Faraday Discuss., 2007, $135,97$.

27 M. Renz, K. Theilacker, C. Lambert and M. Kaupp, J. Am. Chem. Soc., 2009, 131, 16292.

28 (a) For a recent application in the focus of this paper and published during the referring process see: Y. Lu, R. Quardokus, C. S. Lent, F. Justaud, C. Lapinte and S. A. Kandel, J. Am. Chem. Soc., 2010, 132, 13519; (b) The electronic asymmetry resulting from localization of the electron on one side of the oxidized molecule was confirmed through STM images and comparison to theoretical STM images calculated using constrained density-functional theory (CDFT): see ref. 28a.

29 A. Pedone, M. Biczysko and V. Barone, ChemPhysChem, 2010, 11, 1812.

30 For illustrations with examples used in the discussion, see ref. $37 \mathrm{c}$ and 82.

31 F. Barriere and W. E. Geiger, J. Am. Chem. Soc., 2006, 128, 3980.

32 C. Lapinte, J. Organomet. Chem., 2008, 693, 793.

33 (a) P. Hapiot, L. D. Kispert, V. V. Konovalov and J.-M. Saveant, J. Am. Chem. Soc., 2001, 123, 6669; (b) See also D. H. Evans, Chem. Rev., 2008, 108, 2113.

34 J. E. Sutton, P. M. Sutton and H. Taube, Inorg. Chem., 1979, 18, 1017.

35 K. Kay, T. Petrenko, K. Wieghardt and F. Neese, Dalton Trans., 2007, 1552. 
36 F. Paul, B. J. Ellis, M. I. Bruce, L. Toupet, T. Roisnel, K. Costuas, J.-H. Halet and C. Lapinte, Organometallics, 2006, 25, 649.

37 (a) F. Paul, L. Toupet, J.-Y. Thépot, K. Costuas, J.-H. Halet and C. Lapinte, Organometallics, 2005, 24, 5464; (b) F. Paul, G. da Costa, A. Bondon, N. Gauthier, S. Sinbandhit, L. Toupet, K. Costuas, J.-H. Halet and C. Lapinte, Organometallics, 2007, 26, 874; (c) F. Paul, F. Malvolti, G. da Costa, S. Le Stang, F. Justaud, G. Argouarch, A. Bondon, S. Sinbandhit, K. Costuas, L. Toupet and C. Lapinte, Organometallics, 2010, 29, 2491; (d) V. Guillaume, P. Thominot, F. Coat, A. Mari and C. Lapinte, J. Organomet. Chem., 1998, 565, 75.

38 (a) C. E. Powell, M. P. Cifuentes, J. P. Morrall, R. Stranger, M. G. Humphrey, M. Samoc, B. Luther-Davies and G. A. Heath, J. Am. Chem. Soc., 2003, 125, 602; (b) N. Gauthier, N. Tchouar, F. Justaud, G. Argouarch, M. P. Cifuentes, L. Toupet, D. Touchard, J.-F. Halet, S. Rigaut, M. G. Humphrey, K. Costuas and F. Paul, Organometallics, 2009, 28, 2253.

39 (a) W. Kaim, S. Ernst and V. Kasack, J. Am. Chem. Soc., 1990, 112, 173; (b) V. Kasack, W. Kaim, H. Binder, J. Jordanov and E. Roth, Inorg. Chem., 1995, 34, 1924; (c) S. Patra, B. Sarkar, S. Ghumaan, J. Fiedler, W. Kaim and G. K. Lahiri, Dalton Trans., 2004, 754.

40 O. F. Koentjoro, R. Rousseau and P. J. Low, Organometallics, 2001, 20, 4502; M. A. Fox, R. L. Roberts, W. M. Khairul, F. Hartl and P. J. Low, J. Organomet. Chem., 2007, 692, 3277.

41 For further information of the effect of the ligand system on the structure of the Ru complexes see C.-Y. Wong, C.-M. Che, M. C. W. Chan, J. Han, K.-H. Leung, D. L. Phillips, K.-Y. Wong and N. Zhu, J. Am. Chem. Soc., 2005, 127, 13997.

42 N. J. Brown, D. Collison, R. Edge, E. C. Fitzgerald, M. Helliwell, J. A. K. Howard, H. N. Lancashire, P. J. Low, J. J. W. McDouall, J. Raftery, C. A. Smith, D. S. Yufit and M. W. Whiteley, Organometallics, 2010, 29, 1261.

43 N. J. Brown, D. Collison, R. Edge, E. C. Fitzgerald, P. J. Low, M. Helliwell, Y. T. Ta and M. W. Whiteley, Chem. Commun., 2010, 46, 2253.

44 J. Maurer, M. Linseis, B. Sarkar, B. Schwederski, M. Niemeyer, W. Kaim, S. Zális, C. Anson, M. Zabel and R. F. Winter, J. Am. Chem. Soc., 2008, 130, 259.

45 V. Cardieno and J. Gimeno, Chem. Rev., 2009, 109, 3512.

46 S. Rigaut, O. Maury, D. Touchard and P. H. Dixneuf, Chem. Commun., 2001, 373(a) N. Auger, D. Touchard, S. Rigaut, J.-F. Halet and J.-Y. Saillard, Organometallics, 2003, 22, 1638; (b) S. Rigaut, K. Costuas, D. Touchard, J.-Y. Saillard, S. Golhen and P. H. Dixneuf, J. Am. Chem. Soc., 2004, 126, 4072; (c) R. F. Winter and K.-W. Klinkhammer, Organometallics, 2001, 20, 1317; (d) M. P. Cifuentes, M. G. Humphrey, G. A. Koutsantonis, N. A. Lengkeek, S. Petrie, V. Sanford, P. A. Schauer, B. W. Skelton, R. Stranger and A. H. White, Organometallics, 2008, 27, 1716; (e) C.-Y. Wong, C.-M. Che, M. C. W. Chan, K.-H. Leung, D. L. Phillips and N. Zhu, J. Am. Chem. Soc., 2004, 126, 2501.

$47 \mathrm{~K}$. Venkatesan, O. Blacque, T. Fox, M. Alfonso, H. W. Schmalle and Heinz Berke, Organometallics, 2004, 23, 1183; K. Venkatesan, O. Blacque, T. Fox, M. Alfonso, H. W. Schmalle and H. Berke, Organometallics, 2004, 23, 4661.

48 S. Le Stang, F. Paul and Claude Lapinte, Organometallics, 2000, 19, 103; F. de Montigny, G. Argouarch, K. Costuas, J.-F. Halet, T. Roisnel, L. Toupet and C. Lapinte, Organometallics, 2005, 24, 4558; S. I. Ghazala, F. Paul, L. Toupet, T. Roisnel, P. Hapiot and C. Lapinte, J. Am. Chem. Soc., 2006, 128, 2463; Y. Tanaka, J. A. Shaw-Taberlet, F. Justaud, O. Cador, T. Roisnel, M. Akita, J.-R. Hamon and C. Lapinte, Organometallics, 2009, 28, 4656.

49 M.-C. Chung, X. Gu, B. A. Etzenhouser, A. M. Spuches, P. T. Rye, S. K. Seetharaman, D. J. Rose, J. Zubieta and M. B. Sponsler, Organometallics, 2003, 22, 3485.

50 M. Brady, W. Weng, Y. Zhou, J. W. Seyler, A. J. Amoroso, A. M. Arif, M. Bolhme, G. Frenking and J. A. Gladysz, J. Am. Chem. Soc., 1997, 119, 775; R. Dembinski, T. Bartik, B. Bartik, M. Jaeger and J. A. Gladysz, J. Am. Chem. Soc., 2000, 122, 810; C. Herrmann, J. Neugebauer, J. A. Gladysz and M. Reiher, Inorg. Chem., 2005, 44, 6174.

51 H. Jiao, K. Costuas, J. A. Gladysz, J.-F. Halet, M. Guillemot, L. Toupet, F. Paul and C. Lapinte, J. Am. Chem. Soc., 2003, 125, 9511.

52 F. Zhuravlav and J. A. Gladysz, Chem.-Eur. J., 2004, 10, 6510.

53 M. I. Bruce, P. J. Low, K. Costuas, J.-F. Halet, S. P. Best and G. A. Heath, J. Am. Chem. Soc., 2000, 122, 1949; M. I. Bruce, K. Costuas, T. Davin, B. G. Ellis, J.-F. Halet, C. Lapinte, P. J. Low, M. E. Smith, B. W. Skelton, Loic Toupet and A. H. White, Organometallics, 2005, 24, 3864 .
54 M. I. Bruce, K. Costuas, B. G. Ellis, J.-F. Halet, P. J. Low, B. Moubaraki, K. S. Murray, N. Ouddaï, G. J. Perkins, B. W. Skelton and A. H. White, Organometallics, 2007, 26, 3735.

55 M. I. Bruce, K. Costuas, T. Davin, J.-F. Halet, K. A. Kramarczuk, P. J. Low, B. K. Nicholson, G. J. Perkins, R. L. Roberts, B. W. Skelton, M. E. Smith and A. H. White, Dalton Trans., 2007, 5387.

56 M. A. Fox, J. D. Farmer, R. L. Roberts, M. G. Humphrey and P. J. Low, Organometallics, 2009, 28, 5266.

57 A. Klein, O. Lavastre and J. Fiedler, Organometallics, 2006, 25, 635.

58 S. Rigaut, C. Olivier, K. Costuas, S. Choua, O. Fadhel, J. Massue, P. Turek, J.-Y. Saillard, P. H. Dixneuf and D. Touchard, J. Am. Chem. Soc., 2006, 128, 5859 .

59 G.-L. Xu, G. Zu, Y.-H. Ni, M. C. DeRosa, R. J. Crutchley and T. Ren, J. Am. Chem. Soc., 2003, 125, 10057.

60 G.-L. Xu, R. J. Crutchley, M. C. DeRosa, Q.-J. Pan, H.-X. Zhang, X. Wang and T. Ren, J. Am. Chem. Soc., 2005, 127, 13354.

61 J. Maurer, R. F. Winter, B. Sarkar, J. Fiedler and S. Záliš, Chem. Commun., 2004, 1900; J. Maurer, B. Sarkar, B. Schwederski, W. Kaim, R. F. Winter and S. Záliš, Organometallics, 2006, 25, 3701; S. Záliš, R. F. Winter and W. Kaim, Coord. Chem. Rev., 2010, 254, 1383.

62 S. Kheradmandan, K. Heinze, H. W. Schmalle and H. Berke, Angew. Chem., Int. Ed., 1999, 38, 2270; S. Kheradmandan, K. Venkatesan, O. Blacque, H. W. Schmalle and H. Berke, Chem.-Eur. J., 2004, 10, 4872; K Vkatesan, O. Blacque and H. Berke, Dalton Trans., 2007, 1091.

63 G. R. Owen, J. Stahl, F. Hampel and J. A. Gladysz, Chem.-Eur. J., 2008, 14, 73; W. Mohr, J. Stahl, F. Hampel and J. A. Gladysz, Chem.-Eur. J., 2003, 9, 3324; G. R. Owen, S. Gauthier, N. Weisbach, F. Hampel, N. Bhuvanesh and J. A. Gladysz, Dalton Trans., 2010, 39, 5260.

64 (a) D. S. Frohnapfel, B. E. Woodworth, H. H. Thorp and J. L. Templeton, J. Phys. Chem. A, 1998, 102, 5665; (b) J. Sun, S. E. Shaner, M. K. Jones, D. C. O'Hanlon, J. S. Mugridge and M. D. Hopkins, Inorg. Chem., 2010, 49, 1687; (c) S. N. Semenov, O. Blacque, T. Fox, K. Venkatesan and H. Berke, J. Am. Chem. Soc., 2010, 132, 3115.

65 S. Rigaut, J. Perruchon, S. Guesmi, C. Fave, D. Touchard and P. H. Dixneuf, Eur. J. Inorg. Chem., 2005, 447; N. Mantovani, M. Brugnati, L. Gonsalvi, E. Grigiotti, F. Laschi, L. Marvelli, M. Peruzzini, G. Reginato, R. Rossi and P. Zanello, Organometallics, 2005, 24, 405.

66 M. Linseis, R. F. Winter, B. Sarkar, W. Kaim and S. Záliš, Organometallics, 2008, 27, 3321.

67 L. D. Field, A. M. Magill, T. K. Shearer, S. B. Colbran, S. T. Lee, S. J. Dalgarno and M. M. Bhadbhade, Organometallics, 2010, 29, 957; C. Olivier, B.-S. Kim, D. Touchard and S. Rigaut, Organometallics, 2008, 27, 509 .

68 C. Olivier, K. Costuas, S. Choua, V. Maurel, P. Turek, J.-Y. Saillard, D. Touchard and S. Rigaut, J. Am. Chem. Soc., 2010, 132, 5683; C. Olivier, S. Choua, P. Turek, D. Touchard and S. Rigaut, Chem. Commun., 2007, 3100.

69 J.-W. Ying, I. Po-Chun Liu, B. Xi, Y. Song, C. Campana, J.-L. Zuo and T. Ren, Angew. Chem. Int. Ed., 2010, 49, 954.

70 S. N. Semenov, S. F. Taghipourian, O. Blacque, T. Fox, K. Venkatesan and H. Berke, J. Am. Chem. Soc., 2010, 132, 7584.

71 M. Mayor, C. von Hönisch, H. B. Weber, J. Reichert and D. Beckmann, Angew. Chem., Int. Ed., 2002, 41, 1183.

72 T. L. Schull, J. G. Kushmerick, C. H. Patterson, C. George, M. H. Moore, S. K. Pollack and R. Shashidhar, J. Am. Chem. Soc., 2003, 125, 3202 .

73 A. S. Blum, T. Ren, D. A. Parish, S. A. Trammell, M. H. Moore, J. G. Kushmerick, J.-L. Xu, J. R. Deschamps, S. K. Pollack and R. Shashidhar, J. Am. Chem. Soc., 2005, 127, 10010.

74 A. K. Mahapatro, J. Ying, T. Ren and D. B. Janes, Nano Lett., 2008, 8, 2131

75 J.-W. Ying, A. Cordova, T. Y. Ren, G.-L. Xu and T. Ren, Chem.-Eur. J., 2007, 13, 6874

76 B.-S. Kim, J. M. Beebe, C. Olivier, S. Rigaut, D. Touchard, J. G. Kushmerick, X.-Y. Zhu and C. D. Frisbie, J. Phys. Chem. C, 2007, $111,7521$.

77 K. Liu, X. Wang and F. Wang, ACS Nano, 2008, 2, 2315.

78 H. Qi, A. Gupta, B. C. Noll, G. L. Snider, Y. Lu, C. S. Lent and T. P. Fehlner, J. Am. Chem. Soc., 2005, 127, 15218; H. Qi, S. Sharma, Z. Li, G. L. Snider, A. O. Orlov, C. S. Lent and T. P. Fehlner, J. Am. Chem. Soc., 2003, 125, 15250.

79 F. Paul, K. Costuas, I. Ledoux, S. Deveau, J. Zyss, J.-F. Halet and C. Lapinte, Organometallics, 2002, 21, 5229.

80 M. P. Cifuentes, M. G. Humphrey, J. P. Morrall, M. Samoc, F. Paul, C. Lapinte and T. Roisnel, Organometallics, 2005, 24, 4280; M. Samoc, N. 
Gauthier, M. P. Cifuentes, F. Paul, C. Lapinte and M. G. Humphrey, Angew. Chem., Int. Ed., 2006, 45, 7376.

81 N. Gauthier, G. Argouarch, F. Paul, M. G. Humphrey, L. Toupet, S. Ababou-Girard, H. Sabbah, P. Hapiot and B. Fabre, Adv. Mater., 2008, 20, 1952.

82 K. M.-C. Wong, S. C.-F. Lam, C.-C. Ko, N. Zhu, V. W.-W. Yam, S. Roué, C. Lapinte, S. Fathallah, K. Costuas, S. Kahlal and J.-F. Halet, Inorg. Chem., 2003, 42, 7086.

83 Y. Liu, C. Lagrost, K. Costuas, N. Tchouar, H. Le Bozec and S. Rigaut, Chem. Commun., 2008, 6117.
84 K. Motoyama, T. Koike and M. Akita, Chem. Commun., 2008, 5812.

85 Y. Tanaka, T. Ishisaka, A. Inagaki, T. Koike, C. Lapinte and M. Akita, Chem.-Eur. J., 2010, 16, 4762.

86 Y. Lin, J. Yuan, M. Hu, J. C. Cheng, J. Yin, S. Jin and S. H. Liu, Organometallics, 2009, 28, 6402.

87 Y. Tanake, A. Inagaki and M. Akita, Chem. Commun., 2007, 1169.

88 K. A. Green, M. P. Cifuentes, T. C. Corkery, M. Samoc and M. G. Humphrey, Angew. Chem., Int. Ed., 2009, 48, 7867. 